\title{
Microangiopathy triggers, and inducible nitric oxide synthase exacerbates dextran sulfate sodium-induced colitis
}

\author{
Hiroki Saijo ${ }^{1,2}$, Norifumi Tatsumi ${ }^{1}$, Seiji Arihiro ${ }^{2}$, Tomohiro Kato ${ }^{3}$, Masataka Okabe ${ }^{1}$, Hisao Tajiri ${ }^{2,3}$ and \\ Hisashi Hashimoto ${ }^{1}$
}

Ulcerative colitis (UC) is a representative clinical manifestation of inflammatory bowel disease that causes chronic gastrointestinal tract inflammation. Dextran sulfate sodium (DSS)-induced colitis mice have been used to investigate UC pathogenesis, and in this UC model, disturbance and impairment of the mucosal epithelium have been reported to cause colitis. However, how DSS sporadically breaks down the epithelium remains unclear. In this study, we focused on the colonic microcirculation and myenteric neurons of DSS-induced colitis. Moreover, we examined the potential of myenteric neurons as a target to prevent exacerbation of colitis. Fluorescent angiographic and histopathological studies revealed that DSS administration elicited blood vessel disruption before epithelial disorders appeared. Ischemic conditions in the lamina propria induced inducible nitric oxide synthase (iNOS) expression in myenteric neurons as colitis aggravated. When neuronal activity was inhibited with butylscopolamine, neuronal iNOS expression decreased, and the exacerbation of colitis was prevented. These results suggested that DSS-induced colitis was triggered by microcirculatory disturbance in the mucosa, and that excessive neuronal excitation aggravated colitis. During remission periods of human UC, endoscopic inspection of the colonic microcirculation may enable the early detection of disease recurrence, and inhibition of neuronal iNOS expression may prevent the disease from worsening.

Laboratory Investigation (2015) 95, 728-748; doi:10.1038/labinvest.2015.60; published online 4 May 2015

Ulcerative colitis (UC) and Crohn's disease are clinical manifestations of inflammatory bowel disease (IBD) that causes intractable gastrointestinal tract inflammation. ${ }^{1}$ Many possible etiologies, such as genetic factors, ${ }^{2}$ environmental factors, ${ }^{3}$ and autoimmune overactivity, ${ }^{4}$ have been proposed for IBD, but none have been confirmed. Various mouse models of IBD have been introduced to investigate its pathogenesis and pathophysiology, including genetically modified interleukin (IL)-10-deficient mice and mice with colitis chemically induced by the administration of dextran sulfate sodium (DSS) and acetic acid., ${ }^{5,6}$ DSS-induced colitis mice exhibit pathological and pathophysiological features that resemble human UC. However, how DSS induces colitis is not clear. ${ }^{5}$

Many researchers have ascribed DSS-induced colitis to impaired host defense in colonic mucosal epithelium that leads to enterobacteria translocation via dysfunction of the mucosal epithelium. Subsequently, inflammatory cells infiltrate the lamina propria, secrete inflammatory cytokines such as IL- $1 \beta$, IL- 6 , and tumor necrosis factor- $\alpha$ (TNF- $\alpha$ ), and exacerbate inflammation. ${ }^{7}$ Indeed, 4-day incubation of MCA-38, a mouse epithelial cell line, in DSS-containing culture medium reduced cell proliferative activity. ${ }^{8}$ Pathological changes in the epithelium begin $\sim 3$ days after the initiation of oral DSS administration, before colitis. ${ }^{9}$ However, orally administered DSS has been reported to penetrate the lamina propria within 1 day and be engulfed by macrophages. ${ }^{10,11}$ Pathological changes occur sporadically in the mucosa of the distal colon. Consequently, it is unclear why this length of time is necessary to elicit colitis, and the precise pathogenesis of DSS-induced colitis is difficult to define according to the above mechanism.

Disturbances and disruptions of colonic circulation including tissue microcirculation are involved in the pathogenesis of many bowel diseases such as ischemic colitis. In DSS-induced colitis, few observations concerning blood

\footnotetext{
${ }^{1}$ Department of Anatomy, The Jikei University School of Medicine, Tokyo, Japan; ${ }^{2}$ Division of Gastroenterology and Hepatology, Department of Internal Medicine, The Jikei University School of Medicine, Tokyo, Japan and ${ }^{3}$ Department of Endoscopy, The Jikei University School of Medicine, Tokyo, Japan

Correspondence: Professor H Hashimoto, DDS, DMedSc, Department of Anatomy, The Jikei University School of Medicine, 3-25-8 Nishishinbashi, Minato-ku, Tokyo 105-8461, Japan.

E-mail: hashimoto.anat@jikei.ac.jp

Received 18 August 2014; revised 7 March 2015; accepted 31 March 2015
} 
circulation have been reported beyond the finding that vascular permeability was enhanced at an early stage of DSS administration. ${ }^{12}$ Although continuous oral administration of DSS causes hemoccult-positive or bloody stools before pathological changes in epithelium are remarkable, ${ }^{9}$ it is unclear why intraluminal bleeding precedes the onset of colitis and when or how blood vessels are injured.

In this study, we attempted to reveal alterations in the colonic microenvironment and microcirculation induced by DSS administration before colitis onset. Sequential changes in vascular structure and distribution in the colon of DSSadministered mice were three-dimensionally examined with a confocal laser scanning microscope. Hypoxic conditions were analyzed by exploring the expression and localization of hypoxia-inducible factor $1 \alpha(\mathrm{HIF} 1 \alpha)^{13,14}$ and inducible nitric oxide synthase (iNOS). ${ }^{15,16}$ Because iNOS-expressing neuronal hyperactivity might exacerbate DSS-induced colitis, the effect of the anticholinergic agent, butylscopolamine, on colitis progression was also investigated. This study is the first to characterize the role of colonic microcirculation in the onset and progression of DSS-induced colitis.

\section{MATERIALS AND METHODS}

\section{Animals}

Male C57BL/6J mice were purchased from Japan Charles River Laboratories (Kanagawa, Japan). The mice were fed a commercial diet (CE-2; Japan CLEA, Tokyo, Japan) and given tap water to drink ad libitum. They were housed 5 per cage and under a constant temperature of $22^{\circ} \mathrm{C}$ and a 12-h light/ 12-h dark cycle. The following experiments were performed when the mice were 9-10 weeks old.

\section{Experimental Design}

DSS (MW 36 000-50 000, 160110; MP Biomedicals, Tokyo, Japan) was administered to the mice as a $2 \%$ aqueous solution in their drinking water. ${ }^{5}$ Control mice received normal tap water supplied in a bottle. The DSS-administered mice were killed each day and evaluated.

\section{Evaluation of Colitis}

The progression of colitis was evaluated as previously described. ${ }^{17}$ In all mice, weight, stool consistency, and occult blood or gross bleeding were scored each day during the experimental period. Disease activity index (DAI) was determined by calculating the mean of each score. The criteria for scoring are shown in Table 1.

\section{Antibodies}

The primary and secondary antibodies used in this study are summarized in Table 2.

\section{Histological Observation}

At the time of killing, mice were anesthetized with sodium pentobarbital $(50 \mathrm{mg} / \mathrm{kg}$ intraperitoneally) and perfused with $20 \mathrm{ml}$ of a fixative consisting of $4 \%$ paraformaldehyde (PFA)
Table 1 Scoring of disease activity

\begin{tabular}{lcll}
\hline Score & Weight loss (\%) & Stool consistency & $\begin{array}{l}\text { Occult blood or gross } \\
\text { bleeding }\end{array}$ \\
\hline 0 & None & Normal & Normal \\
1 & $1-5$ & & \\
2 & $5-10$ & Loose stools & Hemoccult \\
3 & $10-15$ & & \\
4 & $>15$ & Diarrhea & Gross bleeding
\end{tabular}

Disease activity index $(\mathrm{DAl})=$ average of three scores.

in sodium phosphate buffer (SPB, $\mathrm{pH}$ 7.2) through the left ventricle. Then, the colon was removed and slit open with scissors from the caudal end, and stools were removed with a wooden stick. Another wooden stick was placed under the slit and used to roll up the cleaned colon segment. ${ }^{18}$ The specimen was further fixed in the same fixative, dehydrated through an ascending series of ethanol, embedded in paraffin, and sliced at a thickness of $4 \mu \mathrm{m}$ with a sliding microtome. For routine histological observation, the paraffin sections were stained with hematoxylin and eosin ( $\mathrm{H} \& \mathrm{E})$.

\section{Immunohistochemistry for KI67 and HIF1a on Paraffin Sections}

The paraffin sections were deparaffinized with xylene, rehydrated, and washed with $0.01 \mathrm{M}$ phosphate-buffered saline (PBS, pH 7.4). For KI67 detection, the sections were heated in $0.01 \mathrm{M}$ sodium citrate buffer $(\mathrm{pH}$ 6.0) in an autoclave at $105^{\circ} \mathrm{C}$ for $15 \mathrm{~min}$ to retrieve antigen epitopes. After washing with PBS, the sections were incubated with $10 \%$ normal goat serum at room temperature (RT) for 60 min, and then with the rabbit anti-KI67 antibody at $4{ }^{\circ} \mathrm{C}$ overnight. The sections were rinsed with PBS and incubated with the biotinylated goat anti-rabbit IgG antibody at RT for $60 \mathrm{~min}$. The sections were then washed with PBS and incubated with avidin-biotin-horseradish peroxidase complexes (Vectastain ABC Elite kit PK-6100; Vector Laboratories) at RT for $45 \mathrm{~min}$. After rinses with PBS, the sections were incubated in a coloring solution containing $0.5 \mathrm{mg} / \mathrm{ml}$ of diaminobenzidine tetrahydrochloride (DAB, 349-00903; Dojindo, Kumamoto, Japan) and $0.15 \mu \mathrm{l} / \mathrm{ml}$ of $\mathrm{H}_{2} \mathrm{O}_{2}$ in $0.05 \mathrm{M}$ Tris- $\mathrm{HCl}, \mathrm{pH}$ 7.6, for $30 \mathrm{~s}$. The sections were then washed three times with distilled water. The nuclei were stained with Mayer's hematoxylin. The slides were dehydrated through an ascending series of ethanol, cleared in xylene, and mounted with Entellan new (107961; Merck Millipore, Tokyo, Japan). For HIF1 $\alpha$ detection, the sections underwent the same processes described above without the antigen retrieval step, using rabbit anti-HIF $1 \alpha$ as the primary antibody. Washing with PBS was performed three times for 5 min each. 
Table 2 Antibodies used in this experiment

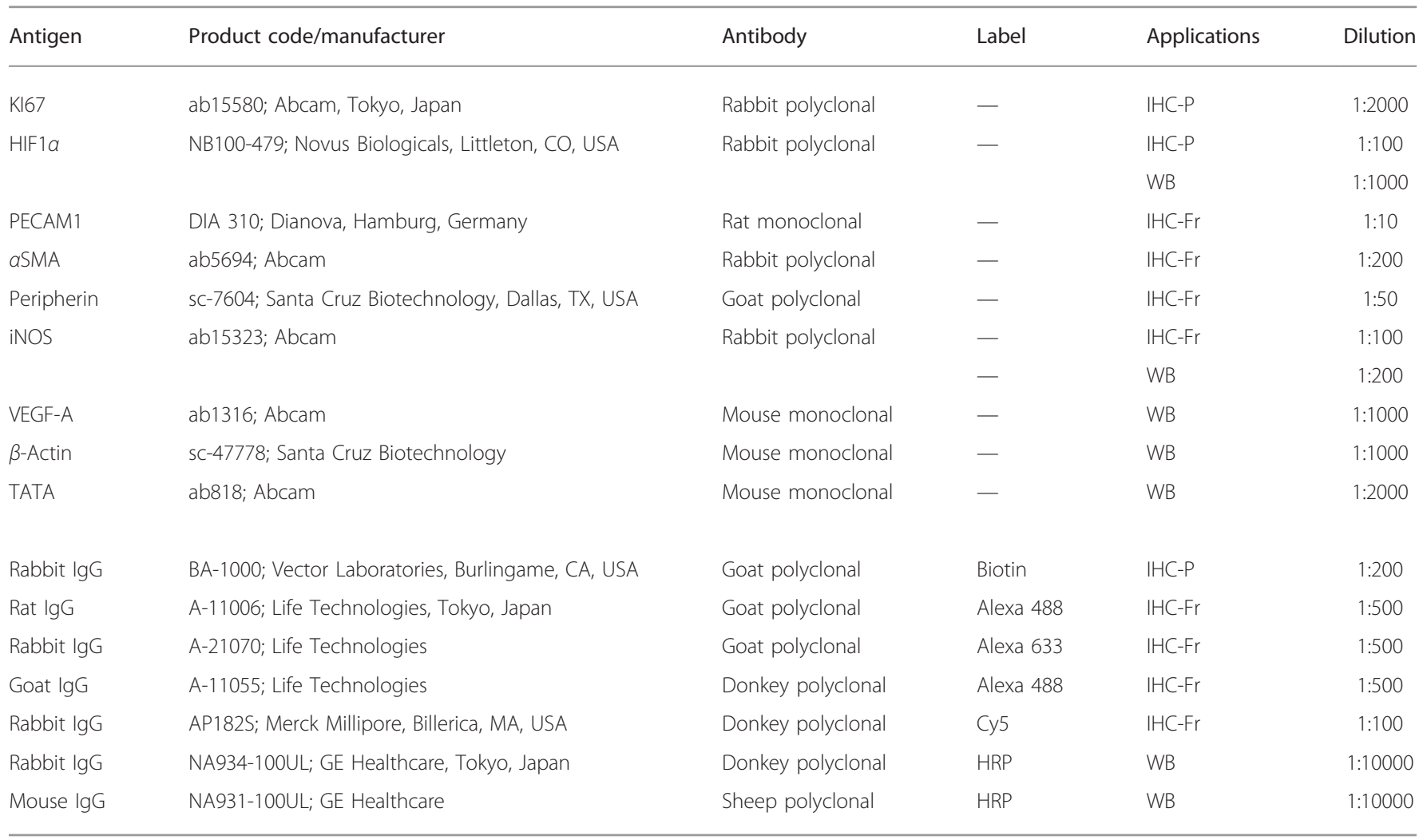

\section{Vascular Cast with RITC-Labeled Gelatin}

Gelatin (gelatin RR; AIBIS, Osaka, Japan) was labeled with rhodamine isothiocyanate (RITC, R1755, Sigma-Aldrich Japan K.K., Tokyo, Japan) as previously described. ${ }^{19}$ Before perfusion, the RITC-labeled gelatin solution (hereafter designated as RITC-gelatin) was dissolved in a hot $\left(\sim 60^{\circ} \mathrm{C}\right)$ water bath, diluted with PBS for a final gelatin concentration of $\sim 10 \%$, and loaded into a $20-\mathrm{ml}$ syringe connected to a $24-$ $\mathrm{G}$ needle by means of a plastic tube. The syringe with plastic tube and needle was kept at $37^{\circ} \mathrm{C}$ in a warm water bath until use.

At the time of killing, mice were anesthetized with sodium pentobarbital and perfused with $20 \mathrm{ml}$ of RITC-gelatin through the left ventricle as blood flowed from the right auricle. After perfusion, the mice were immersed immediately in a chilled fixative consisting of $0.5 \%$ PFA and $15 \%$ ( $\mathrm{vol} / \mathrm{vol}$ ) of a saturated picric acid solution in SPB for $20 \mathrm{~min}$. Then, the colon was removed and further fixed in the same fixative at $4{ }^{\circ} \mathrm{C}$.

\section{Double Immunofluorescence Staining for PECAM1 and aSMA, or for iNOS and Peripherin on Thick Frozen Sections}

The RITC-gelatin-perfused and fixed colon was sliced transversely with razor blades, rinsed several times with cold PBS, and transferred to PBS containing 20\% sucrose and 10\% glycerin for $5 \mathrm{~h}$. The specimen was then rapidly frozen on a freezing stage (K400; Microm Laborgerate, Walldorf, Germany) attached to a sliding microtome (HM400R; Microm Laborgerate) and sectioned at a thickness of $100 \mu \mathrm{m}$. The sections were rinsed with chilled PBS and pretreated with 3\% aqueous solution of sodium deoxycholate overnight at $4{ }^{\circ} \mathrm{C}$. After rinsing with chilled distilled water, the sections were double immunostained for platelet endothelial cell adhesion molecule 1 (PECAM1) and $\alpha$-smooth muscle actin ( $\alpha \mathrm{SMA}$ ), or for iNOS and peripherin. For PECAM1 and $\alpha$ SMA, the pretreated sections were rinsed with chilled PBS, incubated with $10 \%$ normal goat serum overnight at $4{ }^{\circ} \mathrm{C}$, and incubated with a mixture of rat anti-PECAM 1 and rabbit anti- $\alpha \mathrm{SMA}$ antibodies for 3 days at $4{ }^{\circ} \mathrm{C}$. The sections were then rinsed repeatedly with chilled PBS for several hours and incubated with a mixture of Alexa 488-conjugated goat anti-rat IgG and Alexa 633-conjugated goat anti-rabbit IgG antibodies for 2 days at $4{ }^{\circ} \mathrm{C}$. For iNOS and peripherin, the pretreated sections were incubated with $10 \%$ normal donkey serum and then with a mixture of goat anti-peripherin and rabbit antiiNOS antibodies. The secondary antibodies were a mixture of Alexa 488-conjugated donkey anti-goat IgG and Cy5conjugated donkey anti-rabbit IgG antibodies. After incubations, the sections were rinsed repeatedly with chilled PBS, mounted with a mounting medium consisting of $0.05 \mathrm{M}$ Tris-HCl buffered saline ( $\mathrm{pH} 8.0)$ containing $90 \%$ (vol/vol) 
nonfluorescent glycerin and $10 \mathrm{mg} / \mathrm{ml}$ 1,4-diazabicyclo[2.2.2] octane (DABCO), and observed with a Carl Zeiss LSM-510 Meta laser scanning microscope (LSM).

\section{Observation of the Flat-Mounted Whole Distal Colon and Its Thick and Thin Transverse Sections}

After perfusion with RITC-gelatin and fixation as described above, the colon was removed, cut open at the opposite site attached to the mesocolon, and further fixed in the same fixative overnight at $4{ }^{\circ} \mathrm{C}$. The colon was rinsed with cold PBS several times and was treated with $3 \%$ aqueous solution of sodium deoxycholate overnight at $4{ }^{\circ} \mathrm{C}$. After several rinses with cold PBS, the colon was immersed in the mounting medium overnight at $4{ }^{\circ} \mathrm{C}$. Then, the colon was flat mounted on a glass slide with the same mounting medium and was observed with the LSM. After observation, thick transverse sections of the flatmounted colon were obtained by slicing with razor blades and observed transversely with the LSM. The thick sections were then rinsed with cold PBS several times and fixed in 4\% PFA in $0.1 \mathrm{M}$ SPB for $30 \mathrm{~min}$ at RT. After several rinses with SPB, the thick sections were dehydrated with a graded series of ethanol, immersed in a modified hydrophilic resin mixture of 2hydroxypropyl methacrylate, triethylene glycol dimethacrylate, and 2-butoxyethanol at a ratio of 7:0.25:1 containing 0.05\% (wt/ vol) benzoin methyl ether, ${ }^{20}$ and embedded in the same resin mixture to create transverse sections. The resin mixture was cured under ultraviolet irradiation for $1 \mathrm{~h}$ at RT. The resin block was sectioned at a thickness of $2 \mu \mathrm{m}$ with an ultramicrotome (Ultracut UCT; Leica, Tokyo, Japan). Each section was stained with methylene blue and basic fuchsine ${ }^{21}$ and observed with a Carl Zeiss Axio Imager light microscope.

\section{Quantitative Evaluation of Vascular Permeability}

Vascular permeability was determined by the Evans blue dye method $^{22,23}$ with slight modification. Briefly, mice were anesthetized with sodium pentobarbital and received a median abdominal incision. The inferior vena cava was exposed, and $20 \mathrm{mg} / \mathrm{kg}$ of Evans blue dye solution $(10 \mathrm{mg} / \mathrm{ml}$, dissolved in saline solution containing $100 \mathrm{U} / \mathrm{ml}$ of heparin) was injected into it. At $5 \mathrm{~min}$ after injection, the mice were perfused with $20 \mathrm{ml}$ of saline solution through the left ventricle. The distal colon was removed, cleaned, immediately weighed, and placed in a centrifuge tube containing $2.0 \mathrm{ml}$ of formamide. After incubation for $24 \mathrm{~h}$ at $60^{\circ} \mathrm{C}$, the formamide extract was collected, and colorimetric measurements were performed with a Nano Drop 1000 spectrophotometer (ND-1000; Thermo Scientific, Yokohama, Japan) at the absorption maximum for Evans blue $(620 \mathrm{~nm})$. The Evans blue content in the extract was quantified with an external standard curve in formamide ${ }^{24}$ and calculated per gram of tissue.

\section{Endoscopic Assessment of Mucosal Damage and Vascular Permeability}

Properties of the colonic mucosa and vascular permeability of the DSS-administered colon was directly observed by using the endoscope for small animals (AE-C1 and AE-F16070; AVS, Tokyo, Japan). After anesthesia and injection of Evans blue dye as described above, the colon was washed with warmed PBS and inspected thoroughly.

\section{Enzyme-Linked Immunosorbent Assays (ELISAs) of Serum VEGF-A}

Blood was obtained through the inferior vena cava of DSSadministered mice at days $0,2,3,4$ and 5, and serum samples were prepared by centrifugation. Serum levels of vascular endothelial growth factor A (VEGF-A) isoforms were measured with a mouse VEGF-A ELISA kit (MMV00; R\&D Systems; Minneapolis, MN, USA). In brief, $50 \mu \mathrm{l}$ of standard or each serum sample and $50 \mu \mathrm{l}$ of assay diluent RD1N were applied to a well of the assay plate, and mixed by shaking the plate for $1 \mathrm{~min}$. The plate was then sealed and incubated for $2 \mathrm{~h}$ at RT. Each well was washed five times with $1 \times$ wash buffer, and $100 \mu \mathrm{l}$ of $1 \times$ mouse VEGF-A conjugate concentrate was added to each well. Then, the plate was sealed and incubated for $2 \mathrm{~h}$ at RT. The wells were washed five times, and $100 \mu$ l of substrate solution was added to them and incubated for $30 \mathrm{~min}$ at RT. The reaction was terminated by adding $100 \mu \mathrm{l}$ of stop solution and then read with a Corona Grating Microplate Reader SH-1200 Lab (Corona Electric, Ibaraki, Japan) at dual wavelengths of $450 / 540 \mathrm{~nm}$.

\section{Western Blot Analysis of iNOS, VEGF-A, and HIF1a}

At the time of killing, mice were anesthetized with sodium pentobarbital and perfused with $20 \mathrm{ml}$ of cold PBS through the left ventricle, and then the distal colon was removed. The distal colon was homogenized in a lysis buffer $(0.05 \mathrm{M}$ Tris$\mathrm{HCl}, \mathrm{pH} 7.4,0.1 \mathrm{M} \mathrm{NaCl}$, and $1 \%$ Triton X-100) containing complete protease inhibitors (4693116; Roche Diagnostics, Tokyo, Japan) at $4{ }^{\circ} \mathrm{C}$. The supernatant was collected after $30 \mathrm{~min}$ of centrifugation at $13000 \mathrm{~g}$ and assayed for protein concentration using a BCA Protein Assay Kit (23225; Thermo Scientific). The protein concentration in each supernatant sample was adjusted to $5 \mathrm{mg} / \mathrm{ml}$ with the lysis buffer. Of each supernatant sample, $1 \mathrm{ml}$ was mixed with $950 \mu \mathrm{l}$ of Laemmli's sample buffer (161-0737; Bio-Rad Laboratories, Tokyo, Japan) and $50 \mu \mathrm{l}$ of 2-mercaptoethanol and incubated at $95^{\circ} \mathrm{C}$ for $10 \mathrm{~min}$. Then, $8 \mu \mathrm{l}$ of each mixture was subjected to sodium dodecyl sulfate-polyacrylamide gel electrophoresis (SDS-PAGE). The acrylamide concentration was 7.5, 15, and $15 \%$ for the detection of iNOS, VEGF-A, and $\beta$-actin, respectively. After electrophoresis, proteins in the gel were electrotransferred to a Hybond-P polyvinylidene fluoride (PVDF) membrane (2322450; Atto Corporation, Tokyo, Japan). After washing with $0.05 \mathrm{M}$ Tris- $\mathrm{HCl}$ buffered saline $(\mathrm{pH}$ 7.6, hereafter designated as TBS) containing $0.1 \%$ Tween-20 (TBS-T) for $3 \times 5 \mathrm{~min}$, each PVDF membrane was blocked with $0.1 \%$ gelatin, $0.1 \%$ casein, $0.05 \%$ Tween- 20 , and $0.02 \% \mathrm{NaN}_{3}$ in TBS at RT for $1 \mathrm{~h}$. Then, the membrane was washed in TBS-T for $3 \times 5 \mathrm{~min}$ and incubated with the primary antibody (polyclonal rabbit anti-iNOS, monoclonal 
mouse anti-VEGF-A, or mouse anti- $\beta$-actin antibody) at $4{ }^{\circ} \mathrm{C}$ overnight. The membrane was washed in TBS-T for $3 \times 5 \mathrm{~min}$ and incubated with the corresponding ECL horseradish peroxidase-conjugated secondary antibody at RT for $1 \mathrm{~h}$. After washing with TBS-T for $3 \times 5 \mathrm{~min}$, the immunoreaction was detected with a chemiluminescence ECL Prime Western Blotting Detection Reagent (72-AS01-21; GE Healthcare) using a ChemiDoc XRS+ gel imaging system (170-8265J2PC; Bio-Rad Laboratories).

For analysis of HIF $1 \alpha$, the distal colon was similarly removed from mice. Cytosolic proteins and nuclear proteins were extracted from the distal colon using the NE-PER Nuclear and Cytoplasmic Extraction Reagents (78835; Thermo Scientific) according to the manufacturer's instructions. Protein concentration in each extract was adjusted to $2.5 \mathrm{mg} / \mathrm{ml}$ with the extraction reagent. SDS-PAGE and western blotting of each extract were performed as described above using the antiHIF $1 \alpha$ antibody as the primary antibody. The anti-TATAbinding protein antibody and anti- $\beta$-actin antibody were used as nuclear and cytoplasmic loading controls, respectively.

\section{Tissue Preparation for In Situ Hybridization}

Mice were perfused with 4\% PFA in SPB, and the colon was obtained as described above. The colon was sliced transversely with razor blades and further fixed in the same fixative at $4{ }^{\circ} \mathrm{C}$ overnight. Then, the specimen was rinsed several times with cold PBS, immersed in $30 \%$ sucrose in PBS at $4{ }^{\circ} \mathrm{C}$, embedded in Tissue Tek OCT compound (4583D; Sakura, Tokyo, Japan), and frozen. The specimen was sectioned at a thickness of $10 \mu \mathrm{m}$ with a cryostat (CM3050S; Leica, Tokyo, Japan).

\section{Isolation of CDNA Encoding HIF1a and iNOS}

Total RNA was extracted from the colon of a wild-type mouse to isolate HIF $1 \alpha$, and from the colon of a DSS-fed mouse to isolate iNOS, using TRIzol Reagent (15596-026; Life Technologies). First-strand cDNAs were reverse transcribed using PrimeScript II 1st strand cDNA Synthesis Kit (6210A; Takara Bio, Tokyo, Japan). For HIF1 $\alpha$ isolation, specific primers (forward primer, 5'-CATCGACACAGCCTCGATA-3'; reverse primer, 5'-TTCAGCCCTAGCTTCCTTCA-3') were used. For iNOS isolation, two primer sets for independent regions (forward primer, 5'-TCTTGTGTTGGAGGTGACCA-3'; reverse primer, 5'-AGCTGGAAGCCACTGACACT-3' and forward primer,
5'-AAGCCCCGCTACTACTCCAT-3'; reverse primer, 5'-CT CGAGCCTCGTGGCTTTGGGCT-3') were used. PCR using Blend Taq Plus (BTQ-201; Toyobo, Osaka, Japan) was performed under the following conditions: $95^{\circ} \mathrm{C}$ for $30 \mathrm{~s}$, and 30 cycles of $55^{\circ} \mathrm{C}$ for $30 \mathrm{~s}$ and $72{ }^{\circ} \mathrm{C}$ for $1 \mathrm{~min}$. PCR products were ligated into pGEM-T Easy Vector plasmids (A1360; Promega, Tokyo, Japan) and sequenced.

\section{In Situ Hybridization for HIF1a and iNOS}

A digoxigenin-labeled antisense RNA probe was synthesized using the DIG RNA Labeling Kit (T7, 1175025; Roche Diagnostics) with plasmids containing the genes for HIF $1 \alpha$ or two different regions of iNOS. Processes of in situ hybridization were performed as previously described ${ }^{25}$ with some modifications. Briefly, the cryosections were permeabilized with proteinase $\mathrm{K}(5 \mu \mathrm{g} / \mathrm{ml}, 3115828$; Roche Diagnostics) in PBS with $0.1 \%$ Tween- 20 for $10 \mathrm{~min}$ at $37^{\circ} \mathrm{C}$, incubated with $1 \mu \mathrm{g} / \mathrm{ml}$ digoxigenin-labeled riboprobe in hybridization buffer for $16 \mathrm{~h}$ at $70{ }^{\circ} \mathrm{C}$, blocked with $10 \%$ heat-inactivated sheep serum in TBS-T for $30 \mathrm{~min}$ at RT, and incubated with antidigoxigenin antibody conjugated with alkaline phosphatase (1:2000 dilution, 1333089; Roche Diagnostics) in TBS-T containing $1 \%$ heat-inactivated sheep serum for $2 \mathrm{~h}$ at RT. Antibody detection was performed by incubating the sections with $0.2 \%$ nitroblue tetrazolium and $0.2 \%$ 5-bromo-4chloro-3-indolyl-phosphate toluinium in detection solution (0.1 M Tris-HCl, pH 9.5, 0.1 M NaCl, 0.05 M MgCl $2,1 \%$ Tween-20, and $1.25 \mathrm{mM}$ levamisole) for $72 \mathrm{~h}$ at RT.

\section{Quantitative Reverse Transcriptase-PCR (qRT-PCR) Analysis}

Total RNA was isolated from the distal colons using TRIzol reagent and followed by DNase treatment (DNase I, Amplification Grade, 18068-015; Life Technologies) to avoid contaminating genomic DNA. Total RNA $(1.0 \mu \mathrm{g})$ was reverse transcribed using PrimeScript II 1st strand cDNA Synthesis Kit and SYBR green-based qRT-PCR was performed by using SYBR Select Master Mix (4472908; Life Technologies). Primers used were previously described, ${ }^{26-28}$ and they are listed in Table 3.

\section{Induction of Venous Congestion in the Colon}

Venous congestion in the colon was induced by ligation of the inferior mesenteric vein. Mice were anesthetized under

Table 3 Real-time PCR primer sequences

\begin{tabular}{llll}
\hline Gene & Forward primer $\left(5^{\prime}-3^{\prime}\right)$ & Reverse primer $\left(5^{\prime}-3^{\prime}\right)$ & Product size \\
\hline Actb & CAACGGCTCCGGCATGTGC & CTCTTGCTCTGGGCCTCG & 153 bp \\
Vegfa & AGTCCCATGAAGTGTCAAGTTCA & ATCCGCATGATCTGCATGG & 220 bp \\
Hifla & TCATCAGTTGCACTTCCCCAC & CCGTCATCTGTAGCACCATCAC & 198 bp \\
iNos & ATGTGCTGCCTCTGGTCTT & CCTGGACCACTCGTACTTG & 114 bp \\
\hline
\end{tabular}


isoflurane inhalation. A midline abdominal incision was made, and the inferior mesenteric vein was identified and separated from the surrounding tissue. A ligature was tied around the inferior mesenteric vein at the site where it left the colon to join the superior mesenteric vein. Then, the abdominal wall was closed by suturing the abdominal muscle and skin. At the end of anesthesia, mice were allowed to recover on a heating pad. At 24 and $48 \mathrm{~h}$ after ligation, the mice were killed, and the colon was obtained and processed as mentioned above. The paraffin sections were stained with H\&E and immunostained for KI67 and HIF1 $\alpha$. The thick frozen sections were double immunofluorescence labeled for iNOS and peripherin.

\section{Bevacizumab (rhuMAb VEGF) Administration in DSS-Colitis Mice}

Mice were given intraperitoneal injection of bevacizumab $(10 \mathrm{mg} / \mathrm{kg}$ body weight in $0.1 \mathrm{ml}$ saline solution) $24 \mathrm{~h}$ before receiving a course of DSS administration. At $48 \mathrm{~h}$ after the beginning of DSS administration, the mice received the second intraperitoneal injection of the same dose of bevacizumab. At 2, 3, 4, and 5 days of DSS administration, the colon was obtained and processed as described above. Paraffin sections were stained with $\mathrm{H} \& \mathrm{E}$ and HIF1 $\alpha$. Thick frozen sections were double immunofluorescence labeled for iNOS and peripherin.

\section{Butylscopolamine Treatment}

Continuous administration of butylscopolamine was commenced $30 \mathrm{~h}$ after the beginning of DSS administration. Briefly, mice were given 2\% (wt/vol) DSS in their drinking water. At $30 \mathrm{~h}$ of DSS administration, an osmotic minipump (1007D; Alzet, Cupertino, CA, USA) that had been filled with PBS containing butylscopolamine (also known as scopolamine $N$-butylbromide, $5 \mu \mathrm{g} / \mathrm{g}$ body weight/day; S7882-1G; Sigma-Aldrich) was embedded in the subcutaneous tissue of the back ${ }^{29}$ under isoflurane inhalation anesthesia. The DAI of each mouse was calculated each day from the beginning of DSS administration. At 3, 5, and 7 days of DSS administration, the mice were killed, and the colon was obtained and processed as described above. Paraffin sections were stained with H\&E and immunostained for KI67 and HIF1 $\alpha$. Thick frozen sections were double immunofluorescence labeled for PECAM1 and $\alpha$ SMA, or for iNOS and peripherin. The sections that were made by a cryostat were investigated for HIF $1 \alpha$ and iNOS by in situ hybridization. Control mice received only $2 \%(\mathrm{wt} / \mathrm{vol})$ DSS supplied in a bottle.

\section{Statistical Analysis}

Statistical analysis was performed with the Student's $t$-test for comparisons between two groups. Differences between multiple groups were assessed with the Steel multiple comparison test. The $P$-values of $<0.05$ were considered to be statistically significant.

\section{Study Approval}

The experimental design was approved by the institutional animal care and use committee of the Jikei University (23040, 25-049) and performed under the guidelines for animal experimentation.

\section{RESULTS}

The colon was evaluated each day during the experiments, and here we present characteristic changes observed in each experiment.

\section{Vascular Permeability}

At first, to assess the vascular permeability in the distal colon, Evans blue dye solution was intravenously injected. The colonic mucosa was inspected with an endoscope and the content of Evans blue dye was measured by spectrophotometry.

Endoscopic examination of the day 0 colon showed that the mucosa had a smooth surface and was faintly colored with Evans blue. Some fine blood vessels were running in the mucosa. On day 2, a few vessels were dilated and Evans blue dye leaked out to perivascular spaces. On day 3, the leaked Evans blue dye spread in the mucosa and intramucosal hemorrhages were noticed (Figure 1a). The leaked blood and Evans blue dye spread in the mucosa on day 4 and the mucosa was eroded on day 5. The content of Evans blue dye in tissue extract ( $n=4$ each) was gradually increased by the administration of DSS. A significant increase was detected from day 3 to day 5 (Figure $1 \mathrm{~b},{ }^{\star} P<0.05$ ).

\section{Changes in Colorectal Vascular Networks and Epithelium}

The distribution and breakdown of vascular networks during the progression of DSS-induced colitis were investigated in a whole-mount preparation of the distal colon by perfusing the blood vessels with RITC-gelatin. Thick transverse sections obtained from the whole mount were observed again with the LSM. Furthermore, semi-thin resin sections of the thick sections were examined with a light microscopy.

On day 0 , ramified blood vessels were regularly distributed throughout the distal colon. Thick transverse sections revealed blood vessels that branched into the lamina propria running vertically toward the mucosal subepithelial region. The epithelium evenly invaginated into the lamina propria and formed deep crypts (Figure 2a). On day 3, halo-like fluorescence was observed at a few points in the flat mount where vascular density was low, indicating leakage of RITCgelatin from a blood vessel. Thick transverse sections demonstrated RITC-gelatin leakage from a blood vessel running just above the muscularis mucosa, spreading into the lamina propria. On semi-thin sections, the crypts were shortened or lost, whereas the epithelium was unchanged (Figure $2 \mathrm{~b}$ ). No pathological changes were observed in the mucosa obtained from any other region. On day 5, RITCgelatin leakage occurred throughout the distal colon. Thick transverse sections revealed leaked RITC-gelatin spreading 
a

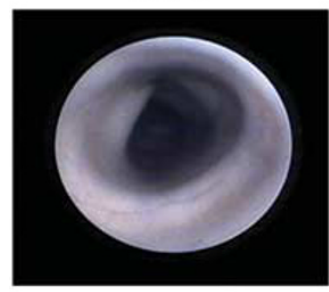

Day 2

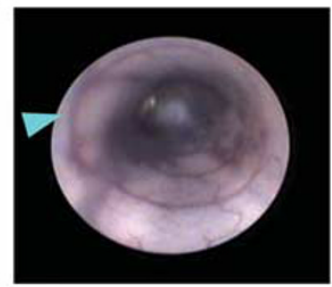

Day 3

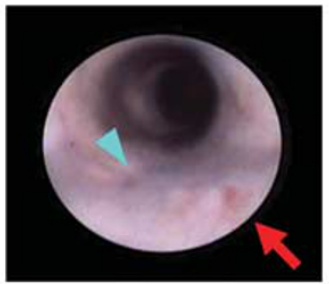

Day 4

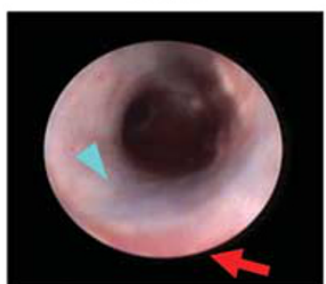

Day 5

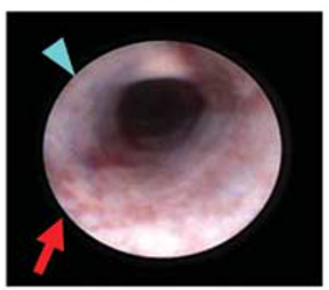

b

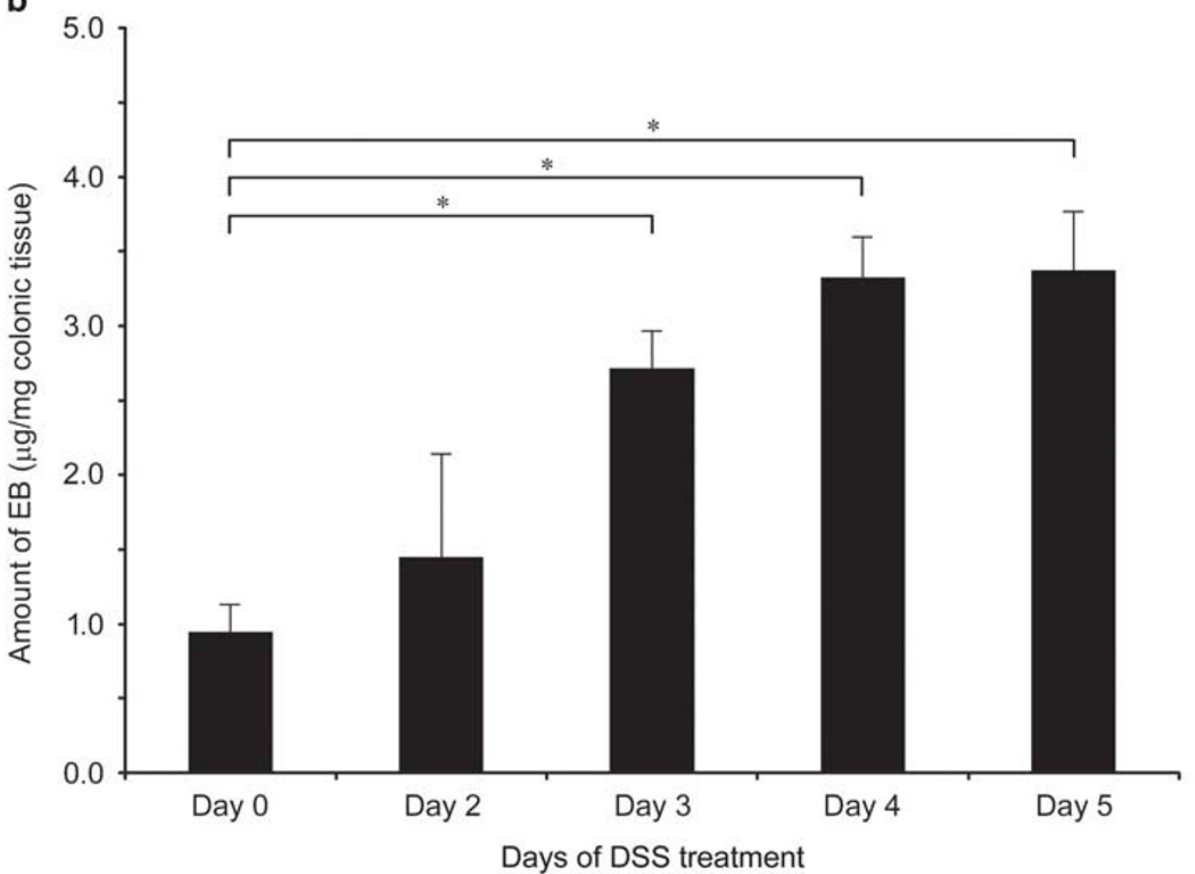

Figure 1 DSS administration increases vascular permeability. (a) Representative endoscopic images of the colon during DSS administration. These images were obtained after intravenous injection of Evans blue dye. On day 0, the colonic mucosa is faintly bluish and fine blood vessels are recognizable. From day 2, bluish smudges, indicating the leakage of Evans blue dye, are discernible in the perivascular region and the leakage spreads day by day (arrowheads). In addition, bleeding in the mucosa begins on day 3, and becomes severer on day 4 and 5 (arrows). (b) Evans blue dye leakage from blood vessels was measured as an indicator of vascular permeability. A significant increase in the amount of Evans blue dye was observed from day 3 to day 5. Data are expressed as mean \pm s.e.m.; $n=4$ each. ${ }^{*} P<0.05$ vs day 0 (WT).

over the lamina propria and accumulating in the subepithelial region. The epithelium as well as crypts were lost, and most blood vessels were expanded (Figure 2c).

\section{Effects of DSS on Vascular Structure, aSMA-Positive Cells, and PECAM1-Positive Cells}

Sequential changes of vascular fine structure and distribution were examined by double immunostaining for $\alpha \mathrm{SMA}$ and PECAM1 on thick frozen sections of the RITC-gelatin perfused colon.

In control animals, endothelial cells indicated by PECAM1 uniformly lined the luminal surface of blood vessels and were surrounded by $\alpha \mathrm{SMA}$-positive vascular smooth muscle cells (Figure $3 \mathrm{a}$ and Supplementary Figure 1A). In the lamina propria, many spindle-shaped $\alpha \mathrm{SMA}$-positive cells were vertically arranged. On day 3 , the blood vessels that ran from the submucosa to the lamina propria appeared constricted as they passed through the muscularis mucosa, and $\alpha \mathrm{SMA}$ immunoreactivity at the vascular wall was decreased in the lamina propria. The arrangement of PECAM1-positive endothelial cells was disorganized in the blood vessels that demonstrated RITC-gelatin leakage. The $\alpha$ SMA-positive vascular wall was thinning and occasionally ruptured. $\alpha \mathrm{SMA}$ immunofluorescence in spindle-shaped cells was diminished. RITC-gelatin leaked into the intercellular space of the vascular wall and the surroundings of the vessels (Figure $3 \mathrm{~b}$ and Supplementary Figure 1B). On day 5, leaked RITC-gelatin spread throughout the lamina propria. The blood vessels indicated by RITC-gelatin and PECAM1 became dense in the lamina propria, and some were tortuous. The number of $\alpha$ SMA-positive cells was increased in comparison with day 3 . At higher magnification, the arrangement of PECAM1- 
a
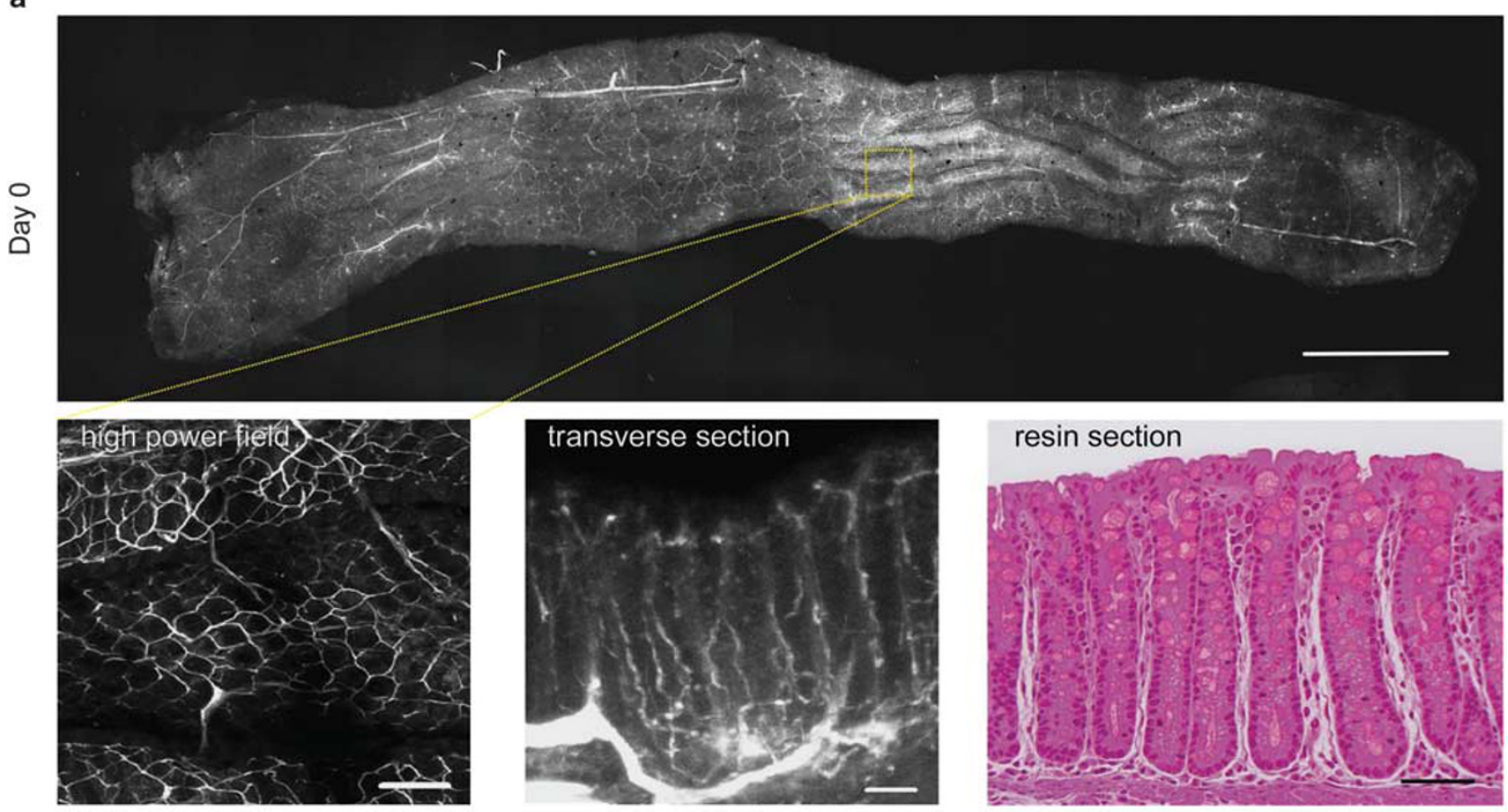

b
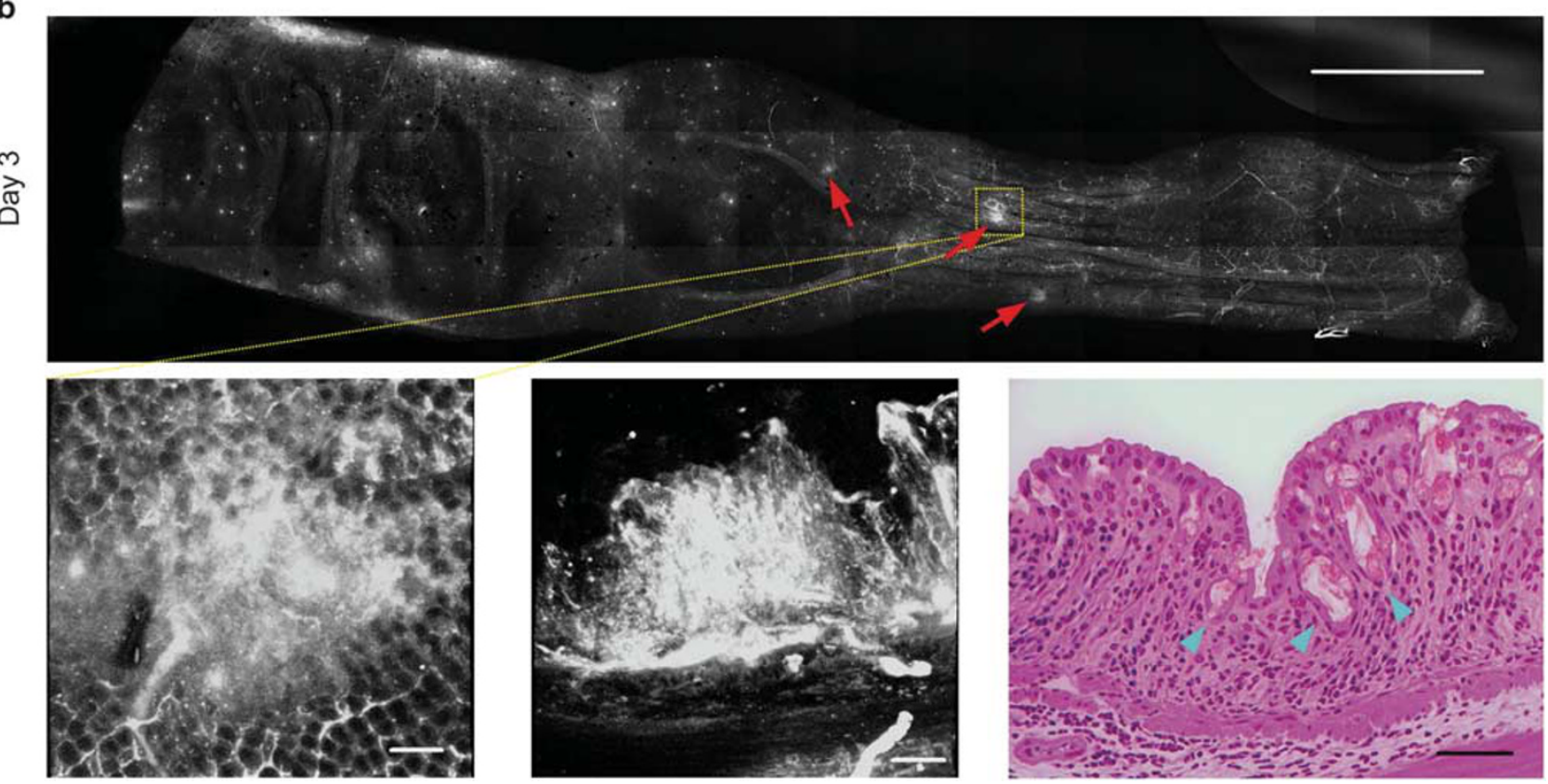

Figure 2 DSS administration injures blood vessels running in the deep layer of the lamina propria and evokes damage to the epithelium. Vascular networks in the distal colon and histology of the colonic mucosa from a wild-type mouse (a) and mice administered DSS for 3 days (b) and 5 days (c). In the upper image, left is rostral and right is anal. The image on the lower left is a high-power view of the yellow rectangular area in the upper flatmount preparation. The lower middle image was obtained from a transverse section through the yellow rectangular area. The image on the lower right was obtained from a semi-thin section of the transverse section. Scale bars: upper, $5 \mathrm{~mm}$; lower left $100 \mu \mathrm{m}$, lower middle and right, $50 \mu \mathrm{m}$. A few halolike spots of fluorescence are present in a flat-mount specimen from day 3 (arrows in b). A high-power view of the spot indicates RITC-gelatin leakage. The transverse section reveals RITC-gelatin leakage spreading from a larger vessel in the deep layer of the lamina propria to the subepithelial region. The crypts in this area are shortened or lost (arrowheads in b). On day 5, a large area of the distal colon emits misty RITC-gelatin fluorescence. Leaked RITC-gelatin accumulates in the subepithelial lamina propria region (arrow in c). The surface epithelium is mostly lost, and no crypt is observed. Some blood vessels are distinguished by their expanded lumen (arrowheads in c). 

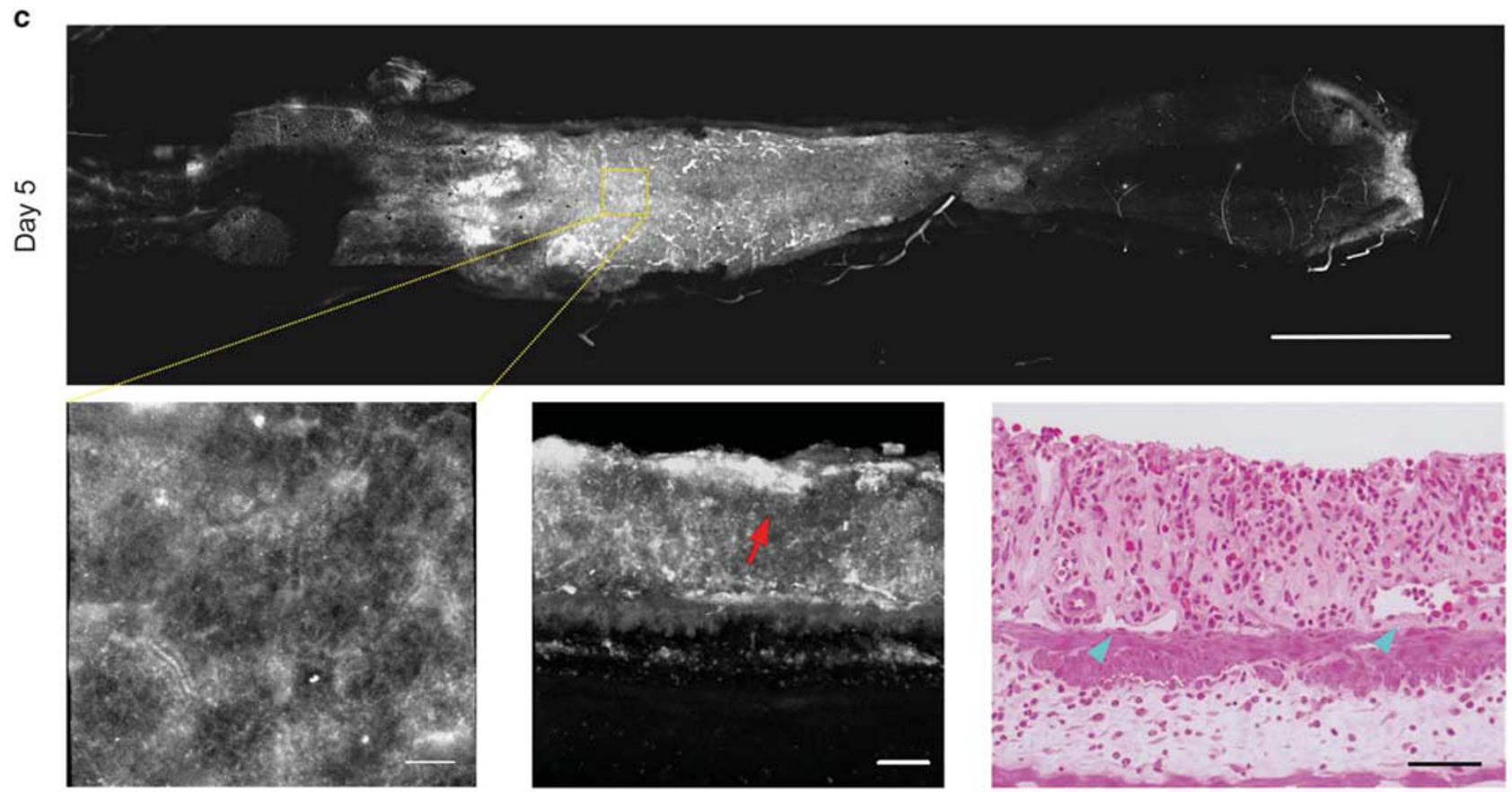

Figure 2 Continued.
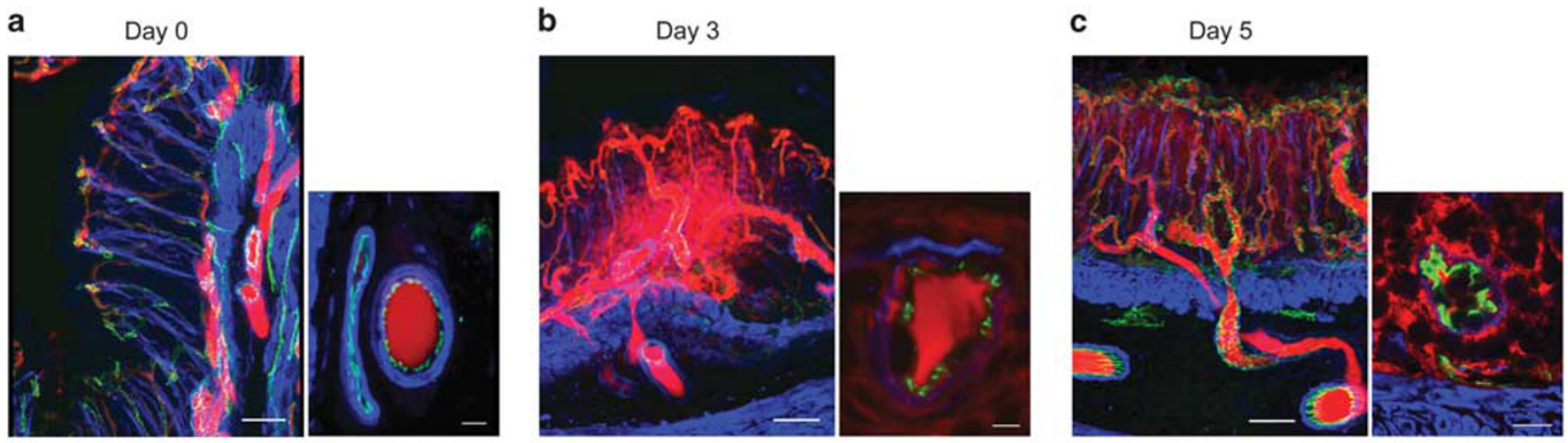

Figure 3 DSS administration causes breakdown of the walls of large vessels running in the deep layer of the lamina propria. Vasculature (red: RITC gelatin) and double immunofluorescence images for PECAM1 (green) and aSMA (blue) from the distal colon on day 0 (a), day 3 (b), and day 5 (c). Scale bars: $50 \mu \mathrm{m}$ (left) and $10 \mu \mathrm{m}$ (right). The arrangement of PECAM1-positive endothelial cells and aSMA-positive smooth muscle cells is disturbed (b, c). RITC-gelatin leakage into the intercellular space of the vascular wall and spreading to the surrounding connective tissue is apparent. Severe stenosis of large vessels is observed.

positive endothelial cells in a larger vessel running just above the muscularis mucosa was disturbed, and RITC-gelatin leaked into intercellular spaces (Figure $3 \mathrm{c}$ and Supplementary Figure 1C).

\section{Pathological Changes of the Distal Colon}

To investigate the mucosal disorder by DSS administration, we performed H\&E stain and immunostaining for KI67 on paraffin sections of the colon.

During first 2 days of DSS administration, no histological changes were observed in the distal colon (Figure 4a).
However, the number of KI67-immunopositive cells at the bottom of crypts was remarkably decreased on day 2 (Figure 4b). On day 3, the crypts became shortened or lost, the arrangement of cells in crypts was distorted, and goblet cells were decreased in number (Figure 4a). The number of KI67-positive cells in the remaining crypts was drastically reduced, and their immunoreactivity markedly diminished, whereas KI67-positive free cells appeared in the deep layer of the lamina propria (Figure 4b). On day 4, the mucosal epithelium was thinning, and the crypts were lost. The goblet cells in the surface epithelium swelled, and blood vessels in 
a
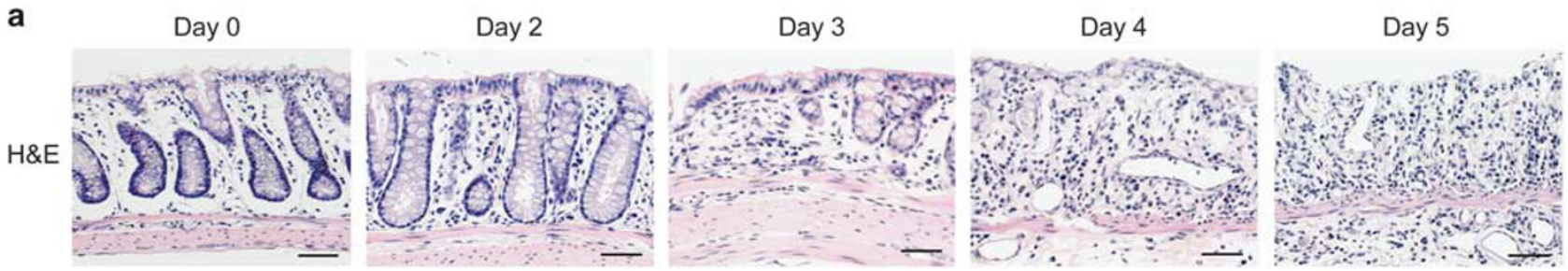

b
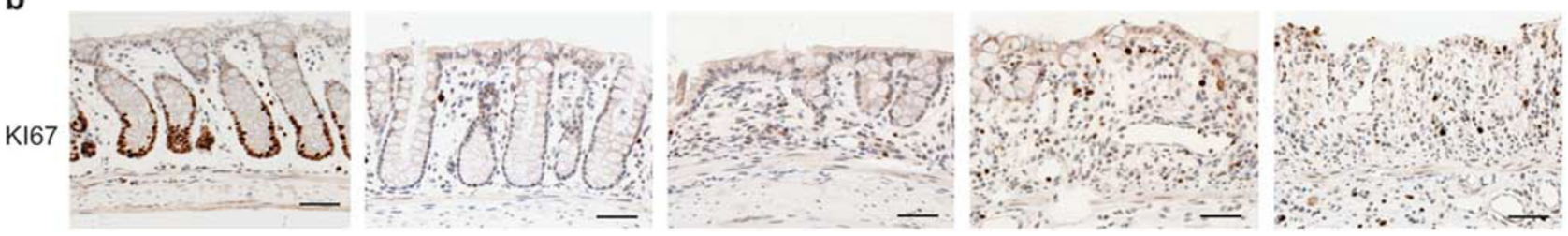

Figure 4 DSS administration diminishes cell division in the proliferative zone of crypts of the distal colon before pathological changes of the epithelium and the crypt become detectable. Paraffin sections of the distal colon from DSS-administered mice were stained with H\&E (a) and immunohistochemically for KI67 (b). Scale bars: $50 \mu \mathrm{m}$. KI67 immunoreactivity is diminished in the proliferative zone of the crypt on day 2, whereas no pathological changes are detectable.

the lamina propria and submucosa were dilated. Inflammatory cells appeared and accumulated in the lamina propria (Figure 4a). KI67-positive cells were lost in the epithelium but conspicuously aberrant in the lamina propria (Figure $4 \mathrm{~b}$ ). On day 5 , the mucosal epithelium had completely disappeared, and inflammatory cells increased and accumulated in the submucosa as well as the lamina propria (Figure 4a). Similarly, KI67-positive cells increased in the lamina propria and submucosa (Figure $4 \mathrm{~b}$ ).

\section{HIF1a, iNOS, Peripherin, and VEGF-A Expressions}

We assumed that the hypoxic condition of the distal colon caused damage to colonic tissues, especially to the crypt and mucosal epithelium. As an indicator of hypoxia, localizations and expressions of HIF1 $\alpha$ protein and mRNA were investigated. In addition, iNOS and VEGF-A expressions were examined because of the following reasons: HIF1 $\alpha$ enhances transcription of genes including iNOS and VEGF-A, ${ }^{13-16}$ iNOS protein level in the colonic mucosa of UC has been correlated with disease activity, ${ }^{30,31}$ and VEGF-A overexpression has been reported to enhance vascular permeability. ${ }^{32}$

On day 0 , epithelial cells of the mucosal surface and the upper region of crypts were immunopositive for HIF $1 \alpha$, whereas no immunoreaction of iNOS was present anywhere in the distal colon (Figures 5a and 6a and Supplementary Figure 2). On day 3, HIF $1 \alpha$ immunoreactivity spread from the mucosal surface to the bottom of remaining crypts (Figure 5a). In addition, endothelial cells of the large vessels in the submucosa and myenteric neurons demonstrated immunopositivity for HIF1 $\alpha$ (Figure 5a). HIF1 $\alpha$ was most prominent on day 3 and decreased thereafter. Mucosal epithelial cells also demonstrated iNOS immunoreactivity. Peripherin-positive nerve fibers running in the lamina propria, submucosa, and myenteric plexus were also immunopositive for iNOS (Figure 6a and Supplementary Figure 2). On day 4 , the thinning epithelium and myenteric neurons were faintly immunoreactive for HIF $1 \alpha$ (Figure 5a). iNOS immunoreactivity on peripherin-positive nerve fibers in the lamina propria was reduced in comparison with day 3 , whereas the perikarya of myenteric neurons remained iNOS immunopositive. Some stromal cells in the lamina propria were immunoreactive for iNOS (Figure 6a and Supplementary Figure 2). On day 5, no cells in the lamina propria demonstrated a positive reaction to HIF $1 \alpha$ and the expression pattern in myenteric neurons was similar to that on day 4 (Figure 5a). iNOS immunoreactivity was scarce in peripherinpositive nerve fibers in the lamina propria, whereas nerve fibers and perikarya in the myenteric plexus were still positive (Figure 6a and Supplementary Figure 2). iNOS-positive stromal cells in the lamina propria were more abundant than on day 4 (Figure 6a and Supplementary Figure 2).

HIF $1 \alpha$ and iNOS mRNA expression was comparable to that of the protein forms (Figures $5 \mathrm{~b}$ and $6 \mathrm{~b}$ ). HIF $1 \alpha$ mRNA was evenly expressed in mucosal epithelial cells on day 0 , and iNOS mRNA appeared in patches (Figures $5 \mathrm{~b}$ and $6 \mathrm{~b}$ ). On day 3 , gene expression of HIFl $\alpha$ was observed in the goblet cells of all crypts and in myenteric neurons that also expressed iNOS mRNA (Figures $5 \mathrm{~b}$ and $6 \mathrm{~b}$ ). iNOS expression in epithelial cells intensified compared with day 0 . On days 4 and 5 , HIF $1 \alpha$ expression was decreased similar to HIF1 $\alpha$ protein immunoreactivity (Figure $5 \mathrm{~b}$ ). In contrast, iNOS expressions in mucosal epithelial cells and neurons were intensified with the progression of DSS administration (Figure 6b).

HIF $1 \alpha$ mRNA in the colonic extract was upregulated significantly on days 2 and 3 , and reverted to the level of day 0 on days 4 and 5 (Figure $5 c,{ }^{\star} P<0.05$ ). Western blot analysis indicated both nuclear and cytoplasmic HIF $1 \alpha$ protein were 
increased on days 2 and 3, and subsequently decreased gradually (Figure 5d). Similarly, mRNA levels and protein contents of iNOS rapidly increased from day 2 (Figures $6 \mathrm{c}$ and $\left.\mathrm{d},{ }^{\star} P<0.05\right)$, whereas peripherin mRNA level $(n=5$ each) did not vary significantly during DSS administration (Figure 6e). a

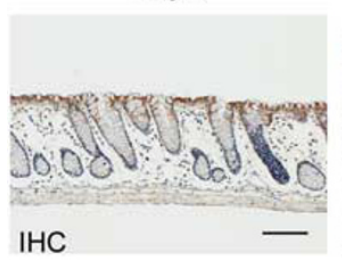

b

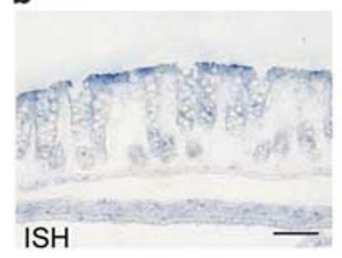

C

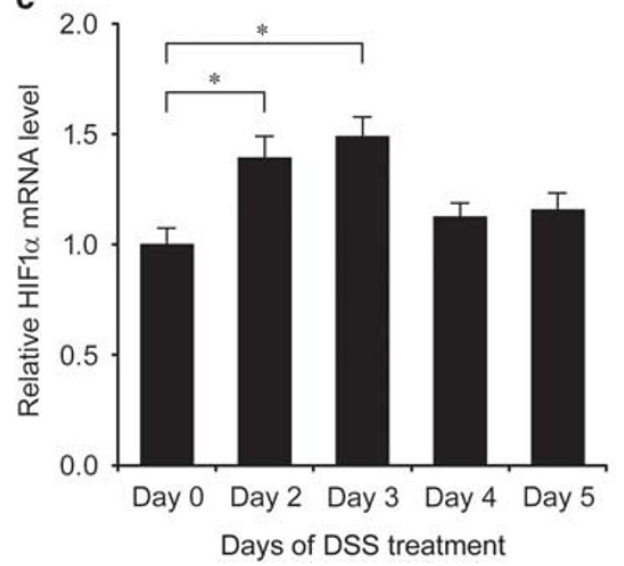

Day 3

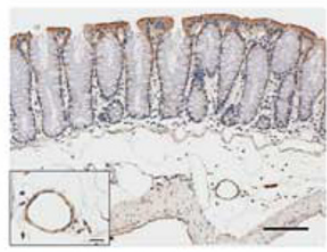

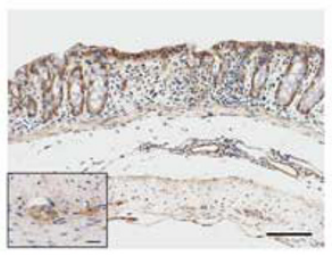

Day 4

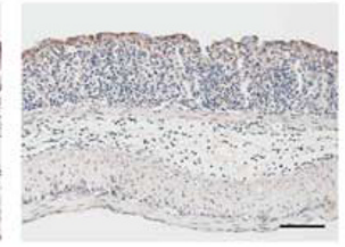

Day 5

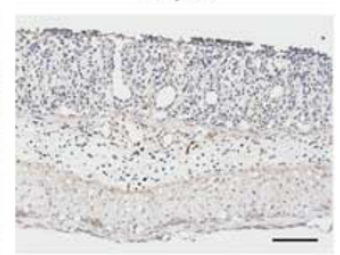

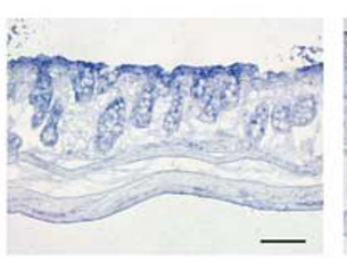

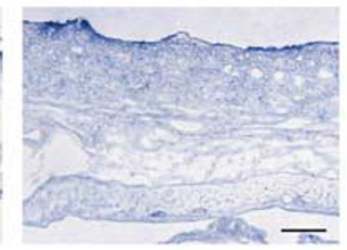

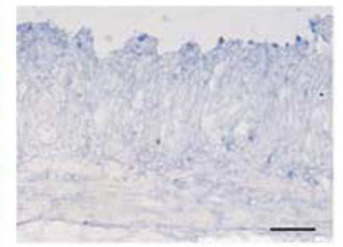

d

Days of DSS treatment

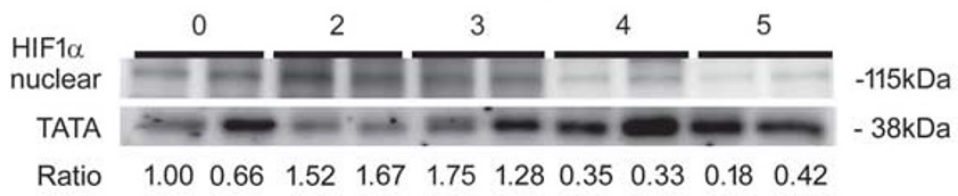

HIF1 $\alpha$ cytoplasm

$\beta$-actin

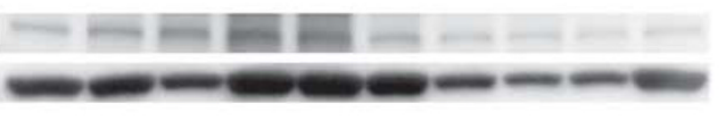

$-115 \mathrm{kDa}$

$-45 k D a$

Ratio

Figure 5 Expression of HIF1a is temporarily upregulated in the early phase of DSS administration, and is then gradually decreased as colonic tissue disintegrates. (a) Immunohistochemistry for HIF1a was performed on paraffin sections of the distal colon from DSS-administered mice. Scale bars: $100 \mu \mathrm{m}$, high-power fields (insets), $20 \mu \mathrm{m}$. (b) In situ hybridization for HIF1a was performed on frozen sections. Scale bars: $100 \mu \mathrm{m}$. HIF1a was most prominent on day 3 and, thereafter, reduced on immunohistochemistry and in situ hybridization. (c) HIF1a mRNA level increased at days 2 and 3 , and subsequently decreased. Data are expressed as mean \pm s.e.m.; $n=5$ each. ${ }^{*} P<0.05$ vs day 0 (WT). (d) Mucosal content of HIF $1 a$ nuclear and cytoplasmic protein was evaluated in extracts of the distal colon from DSS-administered mice by western blot analysis. HIF1a protein levels increased at days 2 and 3 , and subsequently decreased gradually. The upper ratio indicates the relative ratio of HIF1 $a$ in nuclear/TATA-binding protein to the left column on day 0 , and the lower ratio is HIF1 $a$ in cytoplasm/ $\beta$-actin.

Figure 6 DSS administration increases protein and mRNA expression levels of iNOS and VEGF-A in the colon tissues, but not peripherin mRNA and serum VEGF-A protein expression. Immunoreactivity for iNOS is observed in nerve fibers and perikarya. (a) Immunohistochemistry for peripherin and iNOS was performed on 100- $\mu$ m-thick frozen sections of the distal colon from DSS-administered mice. Scale bars: $50 \mu \mathrm{m}$. (b) In situ hybridization for iNOS was performed on frozen sections. Scale bars: $100 \mu \mathrm{m}$. iNOS protein and gene expression in mucosal epithelial cells and neurons is intensified with the progression of DSS administration. (c) The levels of iNOS mRNA were significantly increased from day 2. Data are expressed as mean \pm s.e.m.; $n=5$ each. ${ }^{*} P<0.05$ vs day 0 (WT). (d) Mucosal iNOS protein content was evaluated in extracts of the distal colon from DSS-administered mice by western blot analysis. The ratio is iNOS/ $\beta$-actin and the left end band was used as a standard. The iNOS protein level rapidly increased from day 2. (e) No significant difference was found in peripherin mRNA level between day 0 (WT) and DSS-administered mice. Data are expressed as mean \pm s.e.m.; $n=5$ each. (f) VEGF-A mRNA expression in the colon was significantly increased from day 2 . Data are expressed as mean \pm s.e.m.; $n=5$ each. ${ }^{*} P<0.05$ vs day 0 (WT). (g) Mucosal extracts obtained from the distal colon of mice undergoing DSS treatment revealed significant increase in VEGF-A protein content. The ratio is VEGF-A/ $\beta$-actin and the left end band was used as a standard. (h) Serum VEGF-A protein concentration was measured on days 0 , 2, 3, 4, and 5. No significant difference was seen in serum VEGF-A protein level between day 0 (WT) and DSS-administered mice. Data are expressed as mean \pm s.e. m.; $n=5$ each. 
a
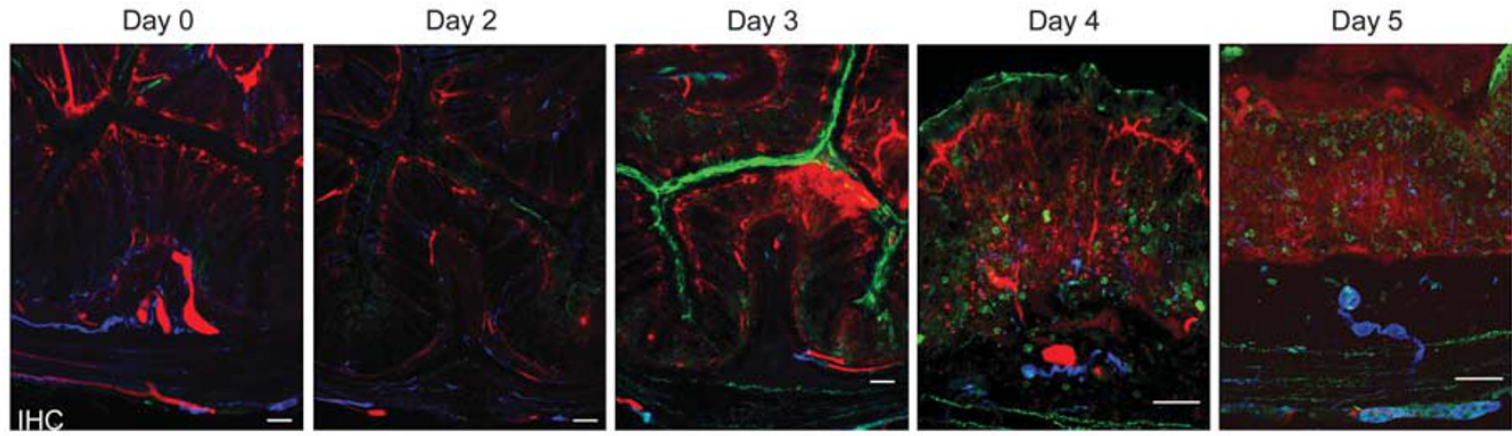

peripherin iNOS Vasculature

b

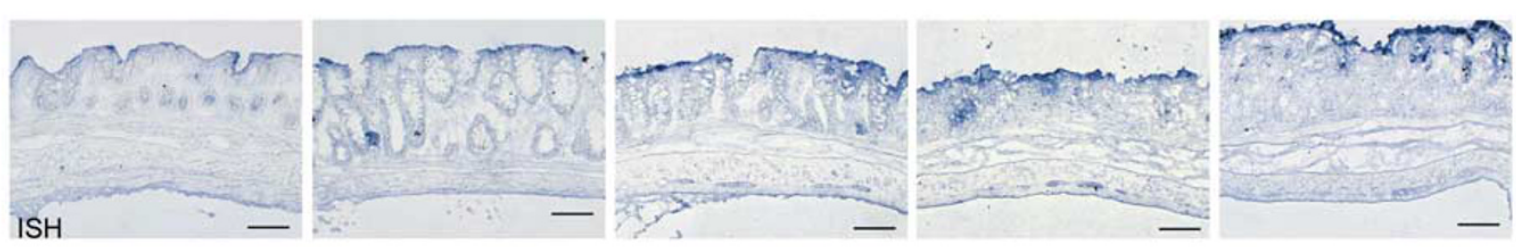

C

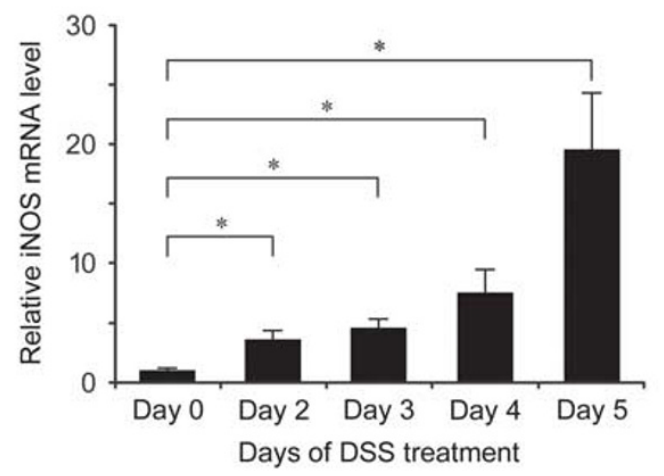

d

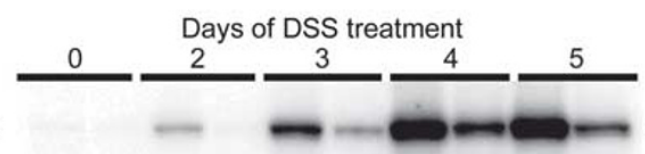

$\beta$-actin

Ratio

e

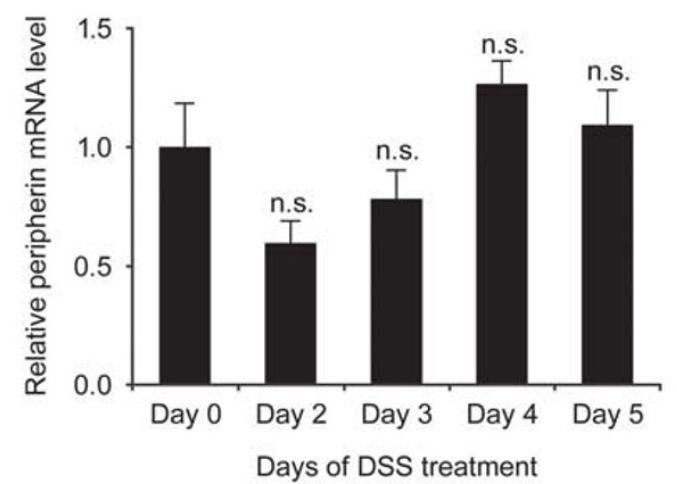

f

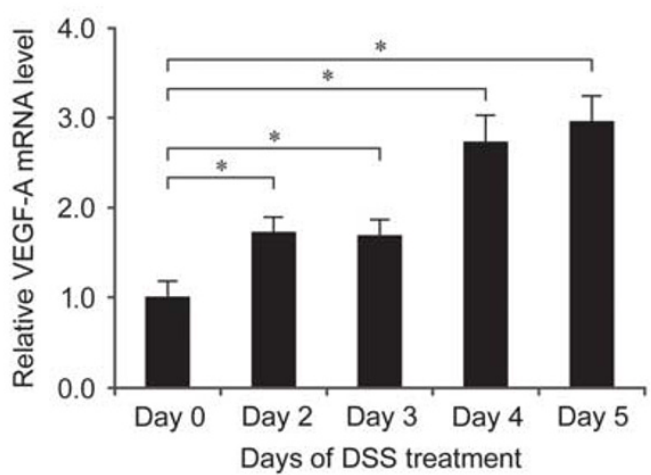

g

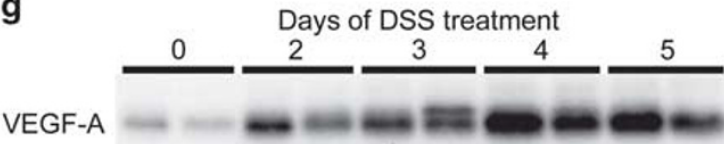

$-23 k D a$

$-131 k D a$

VEGF-A

$\beta$-actin

Ratio $\quad 1.00 \quad 0.723 .353 .194 .236 .416 .827 .259 .533 .15$

h

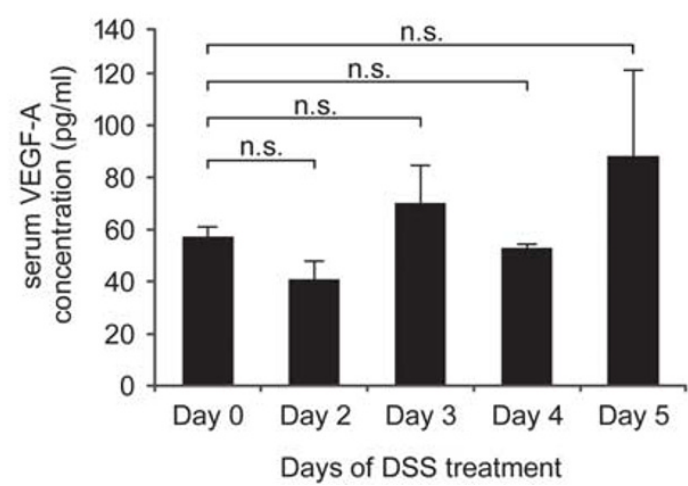


DSS administration significantly increased VEGF-A mRNA levels in the colonic extract from day 2 onward (Figure 6f, $\left.{ }^{\star} P<0.05\right)$. Western blot analysis also showed increase in VEGF-A protein (Figure 6g). However, DSS administration had no significant effect on serum VEGF-A protein level (Figure 6h).

\section{Chronological Changes of the Colonic Mucosa Following Ligation of the Inferior Mesenteric Vein}

The increase in HIF1 $\alpha$ protein level may result from congestion in the distal colon. Therefore, distal colon congestion was artificially induced by inferior mesenteric vein ligation, and pathological changes of the colonic mucosa and HIF1 $\alpha$, KI67, and iNOS expression were investigated over time.

Tributaries of the inferior mesenteric vein, which were wide and dark reddish, ran parallel to branches of the inferior mesenteric artery, which were narrow and whitish, around the distal colon. Upon inferior mesenteric vein ligation, its tributaries were dilated, but inferior mesenteric artery branches were unchanged (Figure $7 \mathrm{a}$ ). At $24 \mathrm{~h}$ after ligation, compared with controls, HIF1 $\alpha$ immunoreactivity appeared in some myenteric neurons, and iNOS-positive cells appeared in the mucosal epithelium, lamina propria, and myenteric plexus. No difference was found in histological structures of the colonic mucosa or KI67 expression pattern (Figure 7b). At $48 \mathrm{~h}$ after ligation, the crypt was markedly reduced, and the submucosa was thickened. In addition to myenteric neurons, vascular smooth muscle cells in the submucosa were HIF $1 \alpha$ immunoreactive. KI67-positive goblet cells were markedly decreased, whereas iNOS fluorescence signal increased in myenteric neurons and mucosal epithelium (Figure 7c).

\section{Effect of Bevacizumab on DSS-Induced Colitis}

We hypothesized that hypoxia due to vascular hyperpermeability by VEGF-A caused mucosal disorder. Therefore, the effects of a VEGF-A inhibitor, bevacizumab, on the progression of DSS-induced colitis were examined.

The colonic mucosa of bevacizumab-infused mice was affected from day 4 (Figures $8 \mathrm{~d}$ and e). The number of crypts decreased, and some crypts were disrupted on days 4 and 5, but no exfoliation of the mucosal epithelium was observed (Figures $8 \mathrm{~d}$ and $\mathrm{e}$ ). HIF $1 \alpha$ immunoreactivity appeared on myenteric neurons from day 2 . The immunoreaction spread from the surface epithelium to the bottom of crypts and to the smooth muscle cells of large submucosal vessels as the day went on (Figures $8 \mathrm{~b}-\mathrm{e}$ ). The blood vessels running in the lamina propria were constricted from day 2 and the leakage of RITC-gelatin from larger vessels in the deep layer of the lamina propria occurred on day 5 (Figures $8 \mathrm{~b}-\mathrm{e}$ and Supplementary Figure 3). Positive immunoreaction for iNOS was observed at the mucosal epithelium and myenteric neurons from day 2. The immunofluorescence was particularly intense in myenteric neurons on day 2 and became more prominent chronologically (Figures 8b-e and Supplementary Figure 3).

\section{Effects of Butylscopolamine on DSS-Induced Colitis}

Anyway, iNOS expression in the myenteric neuron was noticed during exacerbation of DSS-induced colitis. This suggested that iNOS in myenteric neurons had some roles to aggravate the colitis. Therefore, we have attempted to reduce the iNOS expression in myenteric neurons by administering an anticholinergic agent, butylscopolamine, to the DSSinduced colitis mouse. In this experiment, DSS administration was prolonged to 7 days, because the inhibition of peristaltic movement of the gastrointestinal tract by butylscopolamine might delay the action of DSS.

Butylscopolamine infusion prevented relative body weight from declining and disease activity from progressing (Figures $9 \mathrm{a}$ and $\left.\mathrm{b}{ }^{\star} P<0.01\right)$.

The colonic mucosa of butylscopolamine-infused mice was hardly affected by DSS treatment on day 3 and slightly affected on days 5 and 7 (Figures $9 \mathrm{~d}-\mathrm{f}$ ). The number of crypts was decreased, and some crypts were disrupted on days 5 and 7, but no exfoliation of the mucosal epithelium was observed (Figures 9e and f). However, on day 7, the blood vessels that run in the deep layer of the lamina propria were expanded compared with day 5 (Figures 9e and f). HIF1 $\alpha$ expression extended from the surface epithelium to the bottom of crypts, the smooth muscle cells of large submucosal vessels, and myenteric neurons (Figures $9 \mathrm{~d}-\mathrm{f}$ and Supplementary Figure 4). KI67-positive cells were reduced at the bottom of crypts on days 3, 5, and 7 (Figures 9d-f). iNOS expression was hardly observed on peripherin-positive nerve cells on days 3, 5, and 7, as expected (Figures 9d-f and Supplementary Figures 4 and 5). Positive immunoreaction for iNOS was principally observed on stromal cells in the lamina propria on days 5 and 7 (Figures 9e and $f$ and Supplementary Figure 5). Slight RITC-gelatin leakage from blood vessels running just above the muscularis mucosa was observed on day 3 and spread into the deep layer of the lamina propria on day 5 , but did not reach the superficial layer until day 7 (Figures 9d-f and Supplementary Figure 6). VEGFA protein level in the colonic extract was chronologically increased (Supplementary Figure 4). $\alpha S M A$ immunoreactivity on the vascular wall was weaker on days 3 and 5 but increased on day 7. The arrangement of PECAM1-positive endothelial cell was organized throughout the experimental period (Figures 9d-f and Supplementary Figure 6).

\section{DISCUSSION}

Here, we investigated the involvement of colonic microcirculation in the onset of DSS-induced colitis in mice. DSS administration injured the wall of vasculature in the deep layer of the lamina propria before mucosal epithelial cells were disorganized. Subsequently, congestion in the lamina propria affected the epithelium, and finally epithelial cells were exfoliated. During the course of the disease, HIF1 $\alpha$ and iNOS were expressed in neurons of the myenteric plexus. 
Furthermore, continuous infusion of butylscopolamine relieved DSS-induced colitis.

The chronological changes that occurred in DSSadministered mice were categorized into two phases, namely the early phase (days $2-3$ ) and the late phase (days $4-5$ ), and the pathogenic mechanism of DSS-induced colitis is discussed in each phase (Table 4).

In the early phase of DSS-induced colitis, the vascular insufficiency occurred before the mucosal disorder. DSS administration increased vascular permeability before pathological changes in the mucosal epithelium and the crypts have become detectable. Previous studies have reported that rectal bleeding and weight loss occurred within 3-4 days of DSS administration. It has been presumed that damage to the epithelium by DSS allowed the dissemination of proinflammatory intestinal contents, such as bacteria and their products, into the underlying tissue and that colonic inflammation caused rectal bleeding. ${ }^{33-35}$ On the contrary, as orally administered DSS penetrated into the lamina propria within 1 day, ${ }^{10,11}$ vascular smooth muscle and endothelial cells may be directly or indirectly affected by DSS. If not directly, histamine may be a candidate mediator of this effect, because mast cells were increased in the lamina propria of DSS-induced colitis mice. ${ }^{36}$ a

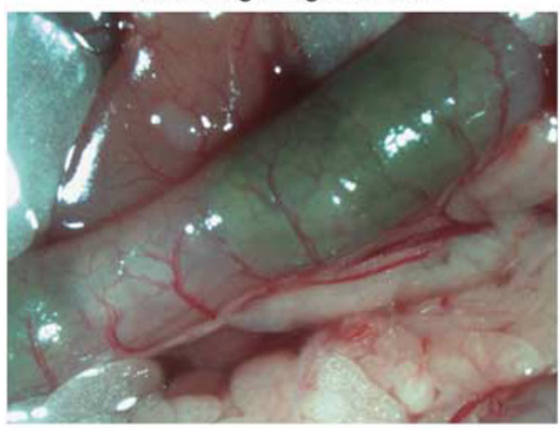

after ligating the vein

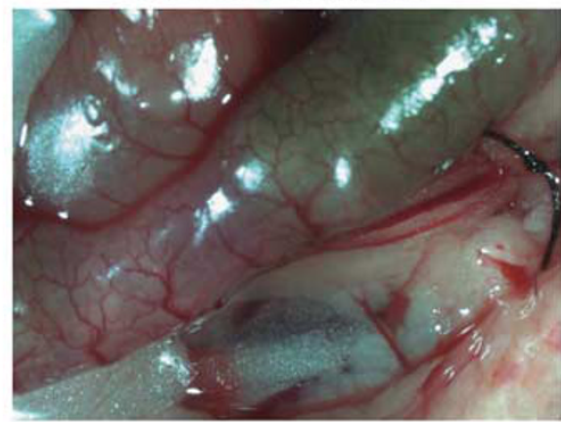

b

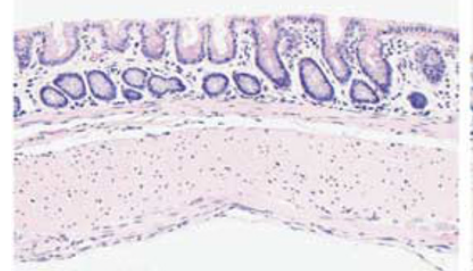

$H \& E$

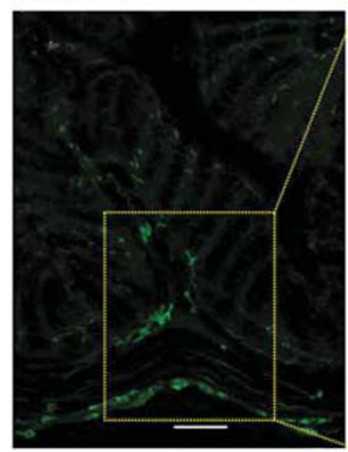

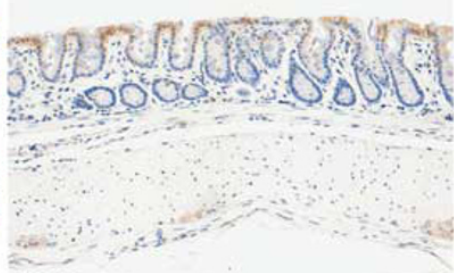

$\mathrm{HIF} 1 \alpha$

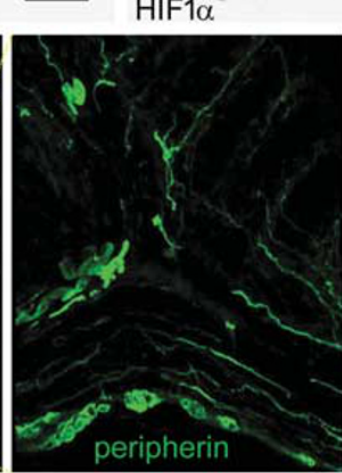

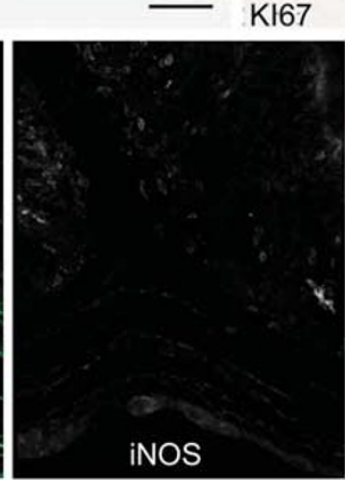
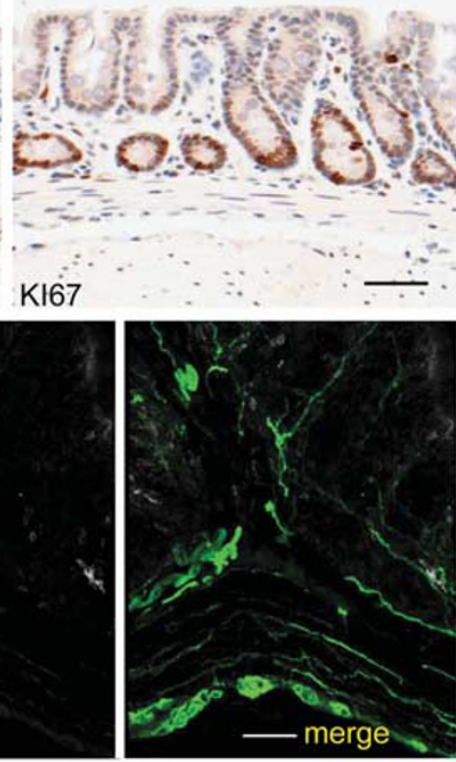

peripherin/ iNOS

Figure 7 Blood flow inhibition induces arrest of cell division in the proliferative zone of crypts and increases HIF1a and iNOS protein content in the colon. (a) Blood vessels surrounding the distal colon before (left) and after (right) ligation of the inferior mesenteric vein. (b, c) H\&E stain,

immunohistochemistry for HIF1a and KI67, and immunofluorescence labeling for peripherin and iNOS at $24 \mathrm{~h}$ (b) and $48 \mathrm{~h}$ (c) after the ligation. Scale bars: $100 \mu \mathrm{m}$ (H\&E, HIF1a, and the left immunofluorescence image), $50 \mu \mathrm{m}$ (KI67 and the right immunofluorescence images). At $24 \mathrm{~h}$, some myenteric neurons demonstrate HIF1a immunoreactivity, and iNOS-positive cells are seen in the epithelium, lamina propria, and myenteric plexus. Histological structures and expression pattern of KI67 are comparable to those on day 0 in Figure 4 . At $48 \mathrm{~h}$, the crypt is reduced, and the submucosa is thickened. Myenteric neurons and vascular smooth muscle cells in the submucosa demonstrate HIF1a immunoreactivity. KI67-positive goblet cells are decreased, whereas iNOS fluorescence signal is increased in myenteric neurons and in the epithelium. 
c
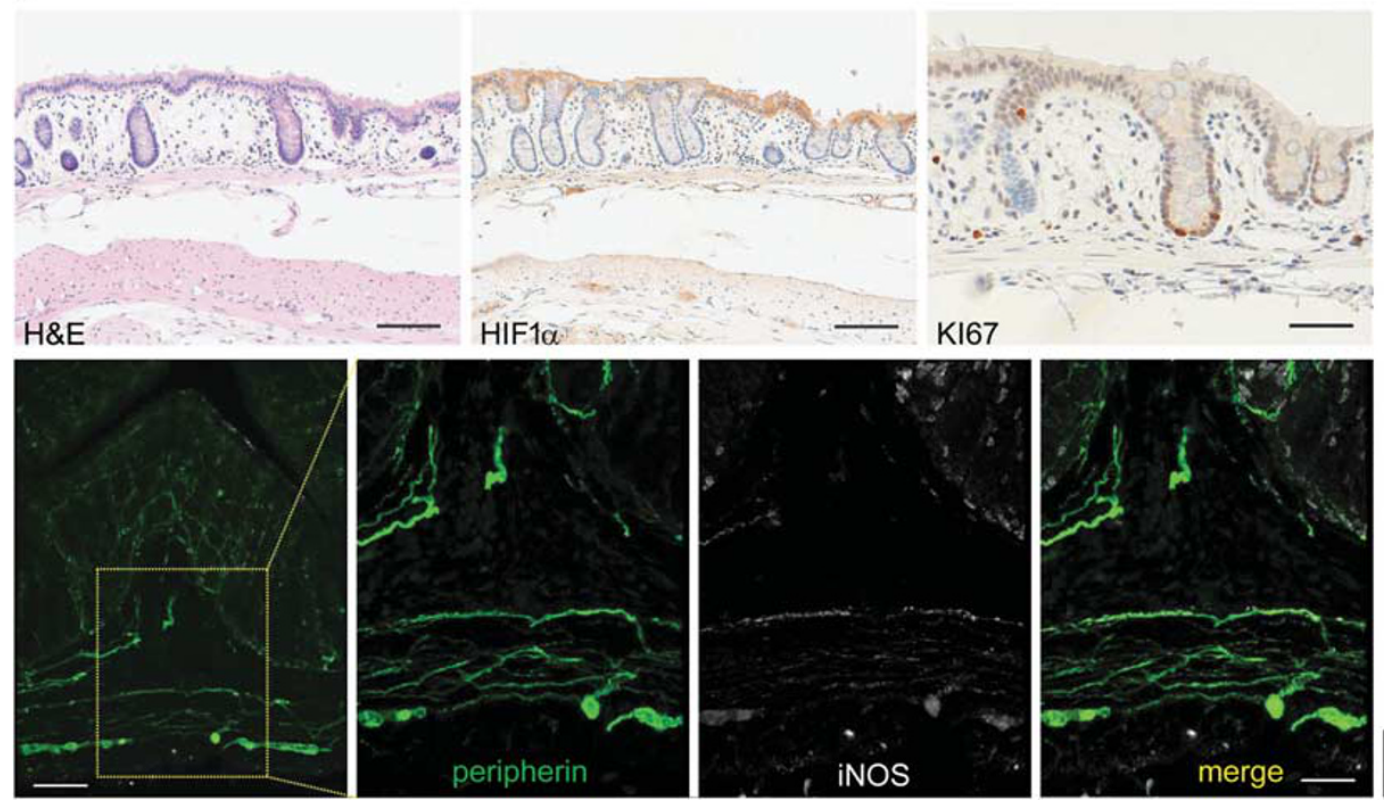

peripherin/ iNOS

Figure 7 Continued.

Experimental congestion by ligating the inferior mesenteric vein also induced a mucosal epithelial disorder resembling DSS-induced colitis (Table 5). This finding supports the notion that DSS causes vascular insufficiency before mucosal disorder. One mouse model of ischemic colitis involves ligating the marginal arteries of the colon, leading to significant bleeding and epithelial exfoliation $72 \mathrm{~h}$ later. ${ }^{37,38}$ However, in the present study, to reveal the effect of congestion on the colon, we ligated the inferior mesenteric vein.

Increased vascular permeability and reduced oxygen supply arising from disturbances in microcirculation might evoke mucosal and cryptal epithelium disorganization. Vascular permeability might be enhanced by VEGF-A. ${ }^{32}$ VEGF-A expression in the colon tissue was increased from day 2, whereas no significant increase in serum VEGF-A level was observed. These observations coincided with the previous report by Cromer et al, ${ }^{39}$ indicating that DSS affected locally in the distal colon. The increase in VEGF-A expression in the early phase would be because of destruction of vascular structure as well as the increase in HIF1 $\alpha$ expression. ${ }^{40}$ Oxygen supply insufficiency was demonstrated by the enhancement of the expression of HIF1 $\alpha$ and iNOS in the colonic mucosa. DSS administration induced HIF1 $\alpha$ expression in submucosal endothelial cells and vascular smooth muscle cells of the large vessels and the perikarya of myenteric plexus neurons, as well as iNOS expression in nerve fibers running in the lamina propria and the muscular layer. A chemical receptor may detect hypoxia in the lamina propria and transmit the information to neurons in the submucosal and myenteric plexus, leading them to express HIF1 $\alpha$ and iNOS. ${ }^{41}$
Inhibition of VEGF-A activity by an anti-VEGF-A antibody, bevacizumab, reduced the mucosal disorder by DSS. Bevacizumab is an anti-human VEGF-A monoclonal antibody and strongly binds human VEGF-A to inhibit its activity. Murine VEGF-A can also bind bevacizumab, but weakly, so that high concentration of bavacizumab was required to inhibit its activity. ${ }^{42}$ Bevacizumab treatment of DSS-administered mice caused capillary constrictions and induced expression of HIF1 $\alpha$ and iNOS. The progression of mucosal damage was delayed, but the leakage of RITC-gelatin from vessels was observed on day 5 . The inhibition of VEGFA activity would prevent vessels from dilating and decrease vascular permeability. This might reduce the pressure of interstitial fluid and minimum blood circulation might be secured. The increases in HIF1 $\alpha$ and iNOS expression occurred in DSS-treated mice in the early phase, irrespective of the bevacizumab treatment. However, bevacizumab treatment retarded the progression of mucosal disorder in the early phase, coinciding with the report on iodoacetamideinduced UC model rats by Tolstanova et al. ${ }^{43}$ These results support the idea that increased vascular permeability by VEGF-A advances the mucosal disorder in the early phase.

In the late phase of DSS administration, iNOS produced by neurons may exacerbate the tissue disorder. The appearance of $\alpha$ SMA-positive cells may indicate that mucosal hypoxia has been ameliorated and restoration has begun. $\alpha$ SMA expression might have increased in proliferating myofibroblasts that are induced by transforming growth factor- $\beta$ (TGF- $\beta$ ), because TGF- $\beta$ expression is increased at the active stage of inflammation in DSS-induced colitis mice. ${ }^{44}$ Decreased HIF1 $\alpha$ expression after day 3 may also indicate that 
congestion was relieved by leakage of the congested blood and interstitial fluid from the lamina propria into the colonic lumen and temporary improvement of colonic blood flow. However, many iNOS-positive cells also appeared in the lamina propria. These iNOS-positive cells would be CD11bpositive macrophages derived from circulating monocytes. ${ }^{45}$ Although the appearance of iNOS-positive cells correlates with the activity of experimental colitis and IBD, ${ }^{30,31}$ whether a

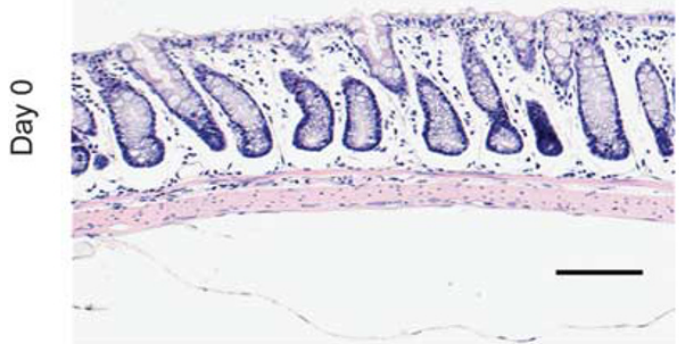

b
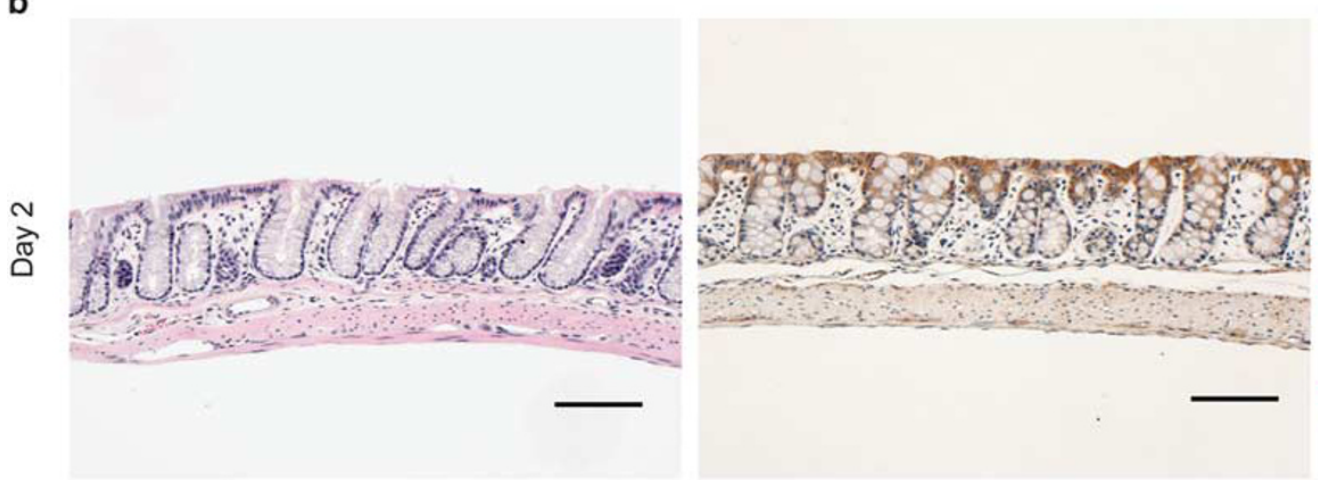

C
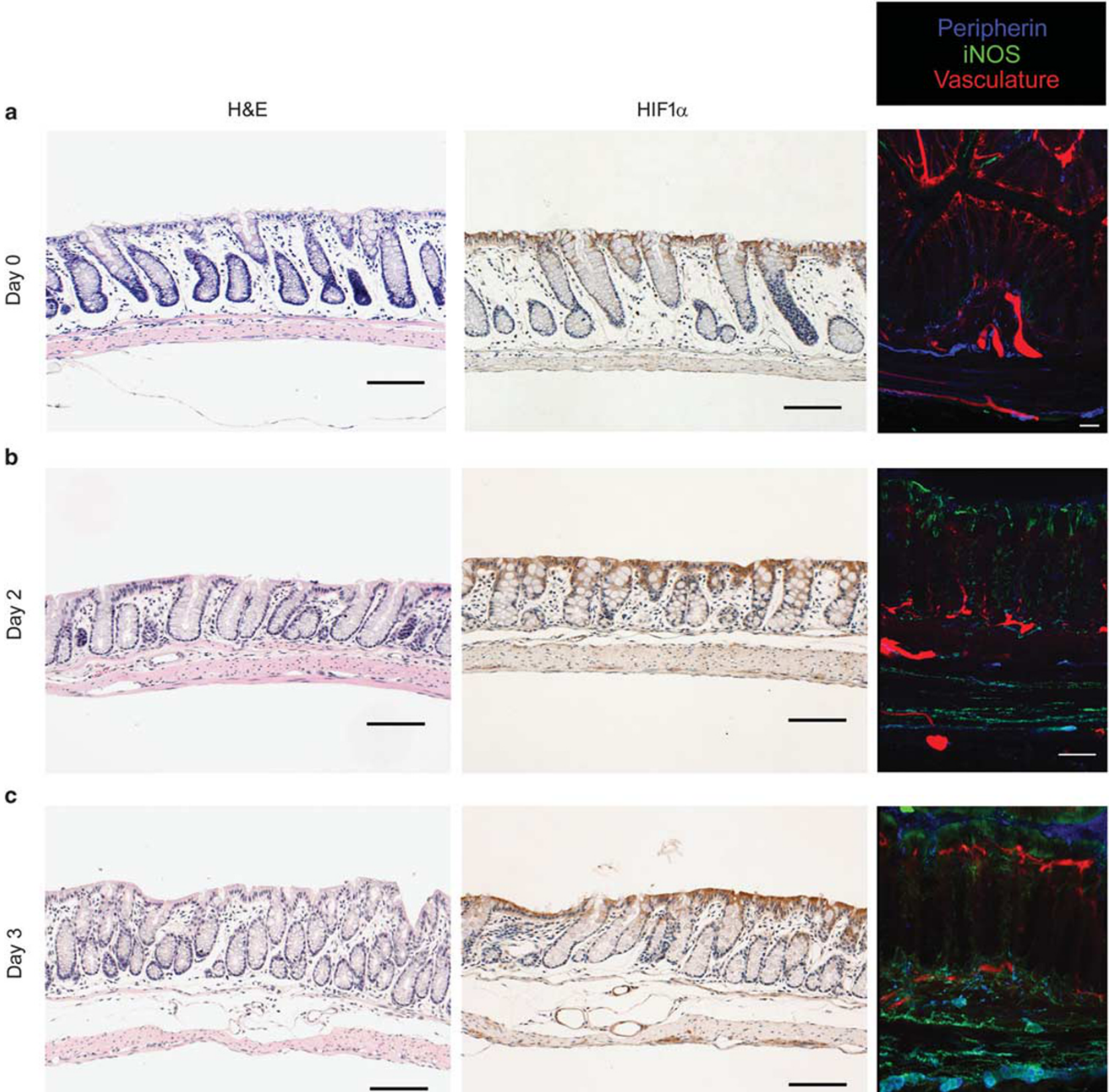

$\mathrm{HIF} 1 \alpha$
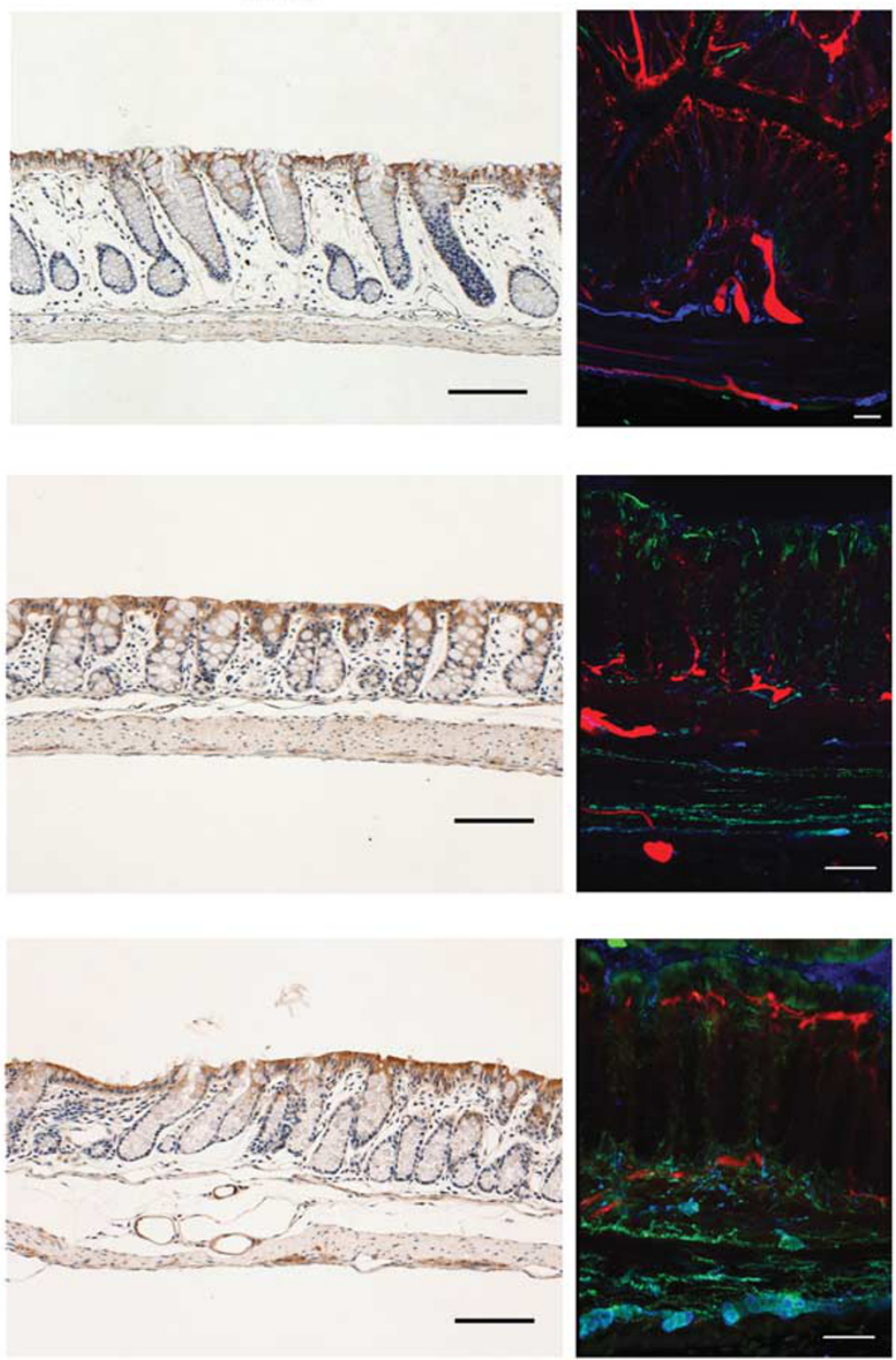

Figure 8 Administration of bevacizumab to DSS-induced colitis mice causes vasoconstriction and upregulation of HIF1a and iNOS, and the mucosal membrane disorder is slight. (a-e) H\&E staining and immunohistochemistry for HIF1a were performed on paraffin sections of the distal colon from bevacizumab- and DSS-administered mice. Vasculature (red: RITC-gelatin) and double immunofluorescence images for iNOS (green) and peripherin (blue) of the distal colon on day 0 (a), day 2 (b), day 3 (c), day 4 (d), and day 5(e). Scale bars: $100 \mu \mathrm{m}$ (left two images) and $50 \mu \mathrm{m}$ (right image). Histological structures of bevacizumab-infused mice are slightly affected by DSS treatment, but the crypts become shortened or lost on days 4 and 5 (d, e). HIF1a immunoreactivity extends from the surface epithelium to the bottom of crypts, and the smooth muscle cells of large vessels in the submucosa and the myenteric neurons are immunopositive as well (c-e). The blood vessels that run in the lamina propria are narrow from day 2 (b-e) and RITC-labeled gelatin leaks from the blood vessels in the deep layer of the lamina propria (e). iNOS protein in mucosal epithelial cells and neurons appear from day 2 , and they are intensified with the progression of DSS administration (b-e). 

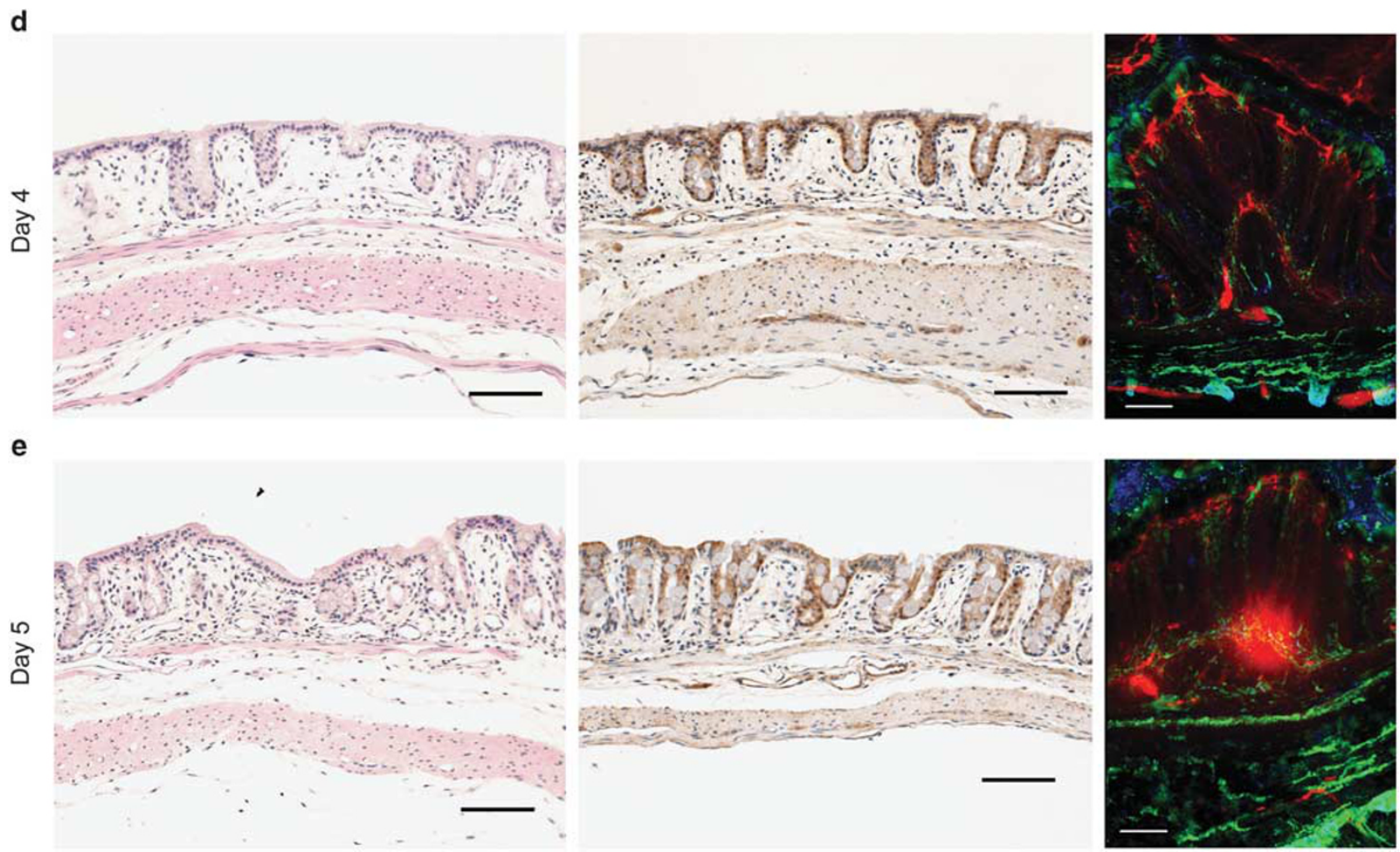

Figure 8 Continued.

nitric oxide (NO) produced by iNOS inhibits the inflammation remains unclear. Some studies have reported that NO worsened colitis, ${ }^{46,47}$ and others reported that it inhibited inflammation. ${ }^{31}$ McCafferty et al ${ }^{48}$ reported that the 2,4,6trinitro benzene sulfonic acid (TNBS) colitis worsened when iNOS-positive white blood cells that inhibited early-stage inflammation were no longer present. Moreover, Shifrin et $a l^{49}$ reported that coadministration of scopolamine with rivastigmine to DSS-induced colitis mouse significantly increased the number of CD11b-expressing cells in the colon compared with those given rivastigmine alone but showed no difference in the DAI score. Therefore, we speculated that increased neuronal iNOS may be involved in exacerbating colitis, whereas iNOS in macrophages in the lamina propria may inhibit the inflammation or have no relation with aggravation of inflammation.

We hypothesized that if neuronal iNOS exacerbated DSSinduced colitis, inhibition of their activity by muscarinic receptor blockade would relieve the inflammation. Butylscopolamine, also known as scopolamine- $N$-butylbromide, is a quaternary ammonium derivative of scopolamine, cannot pass the blood-brain barrier, and works only in the peripheral internal organs without a central effect. ${ }^{50,51}$ Butylscopolamine administration averted the late phase of colitis; that is, the DAI remained low and colonic mucosa ulceration was not observed, whereas the leakage of RITC-gelatin from vessels and arrest of cell proliferation in the crypt were still observed. The downregulation of iNOS by butylscopolamine might reduce VEGF-A expression, as reported by Abe et al..$^{52}$ The inhibitory effect of butylscopolamine on DSS-colitis might be exerted partly by the downregulation of VEGF-A. These results suggest that neuronal iNOS participated in exacerbating inflammation and that butylscopolamine administration did not prevent the early phase of the DSS-induced colitis such as microangiopathy and hypoxia condition of tissues, but did inhibit the exacerbation of inflammation and vascular hyperpermeability by reducing neuronal excitation.

On the basis of these results, we present a novel pathogenic mechanism of DSS-induced colitis. Past studies have reported that the mucosal epithelium is affected by DSS cytotoxicity and that colitis results from impaired host defense of the colonic mucosal epithelium. ${ }^{53,54}$ In contrast, the present study demonstrated that microcirculation impairment in the colonic mucosa precedes disturbance of the mucosal epithelium. Our novel pathogenic mechanisms as well as the classic mechanism are summarized in Figure 10.

The following two problems should be address in future research. First, why does DSS selectively disrupt the blood vessels running in the deep layer of the lamina propria? Second, what is the difference between iNOS in stromal cells and that in neurons? Although we concluded that neuronal iNOS exacerbated DSS-induced inflammation, it is unclear 
a

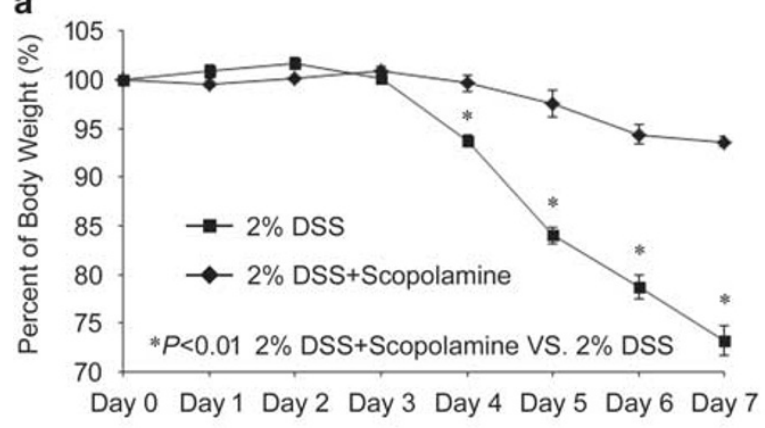

Days of DSS treatment b

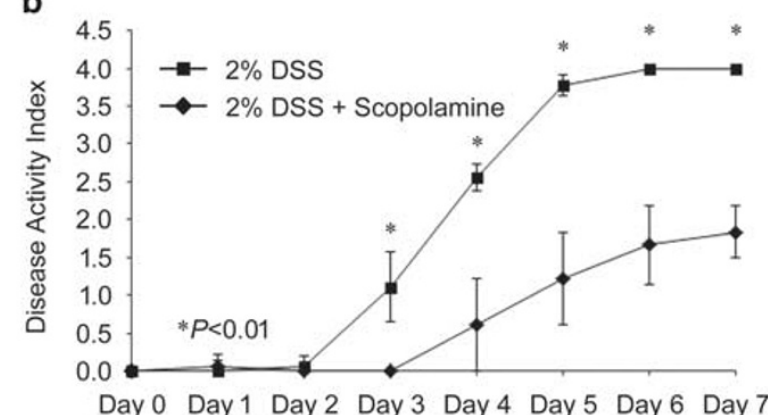

Days of DSS treatment
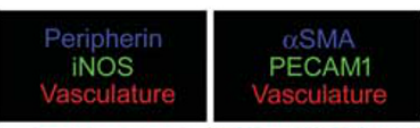

C

H\&E

HIF1 $\alpha$
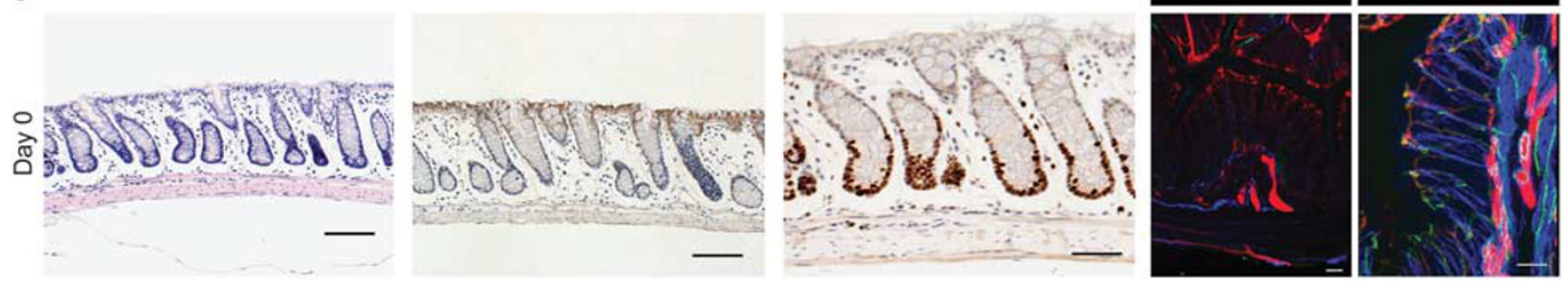

d
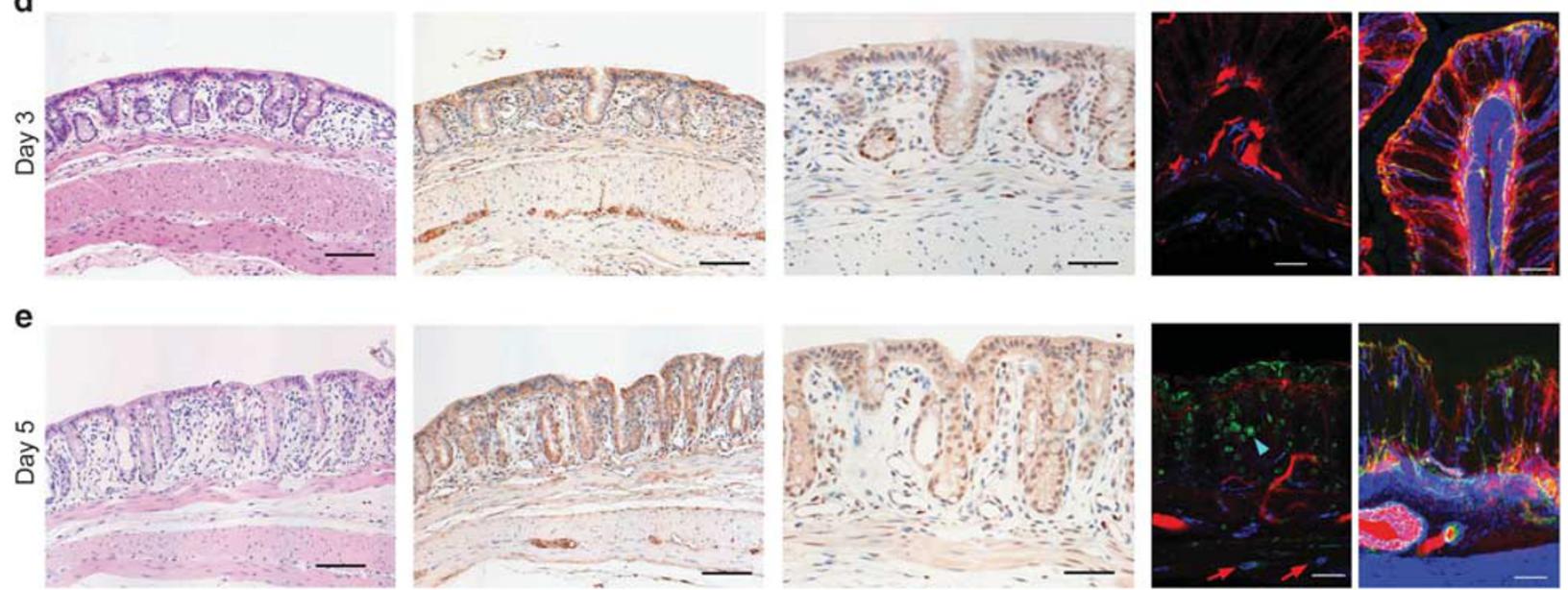

f
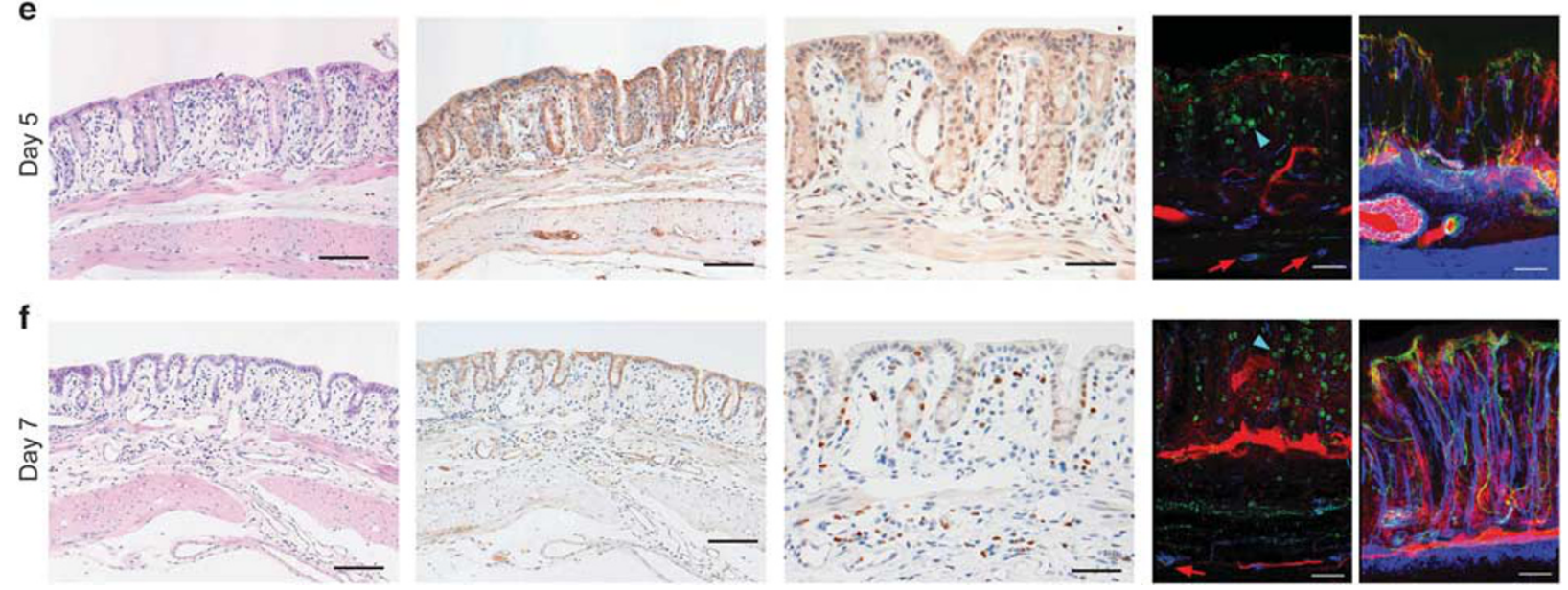

Figure 9 Administration of butylscopolamine alleviates DSS-induced colitis. (a) Relative body weights. Data are expressed as mean \pm s.e.m. $(n=6$ each). ${ }^{*} P<0.01$. (b) Disease activity index. Data are expressed as mean \pm s.e.m. $\left(n=6\right.$ each). ${ }^{*} P<0.01$. (c-f) H\&E staining and immunohistochemistry for HIF1a and KI67 were performed on paraffin sections of the distal colon from butylscopolamine- and DSS-administered mice. Vasculature (red: RITC-gelatin) and double immunofluorescence images for iNOS (green) and peripherin (blue) or for PECAM1 (green) and aSMA (blue) of the distal colon on day 0 (c), day 3 (d), day 5 (e), and day 7 (f). Scale bars: $100 \mu \mathrm{m}$ (left two images) and $50 \mu \mathrm{m}$ (right three images). Histological structures of butylscopolamine-infused mice are slightly affected by DSS treatment (d, e). However, on day 7, the blood vessels that run in the deep layer of the lamina propria are expanded compared with day 5 (e, f). HIF1a immunoreactivity extends from the surface epithelium to the bottom of crypts, and the smooth muscle cells of large vessels in the submucosa and the myenteric neurons are immunopositive (d-f). KI67-positive cells are reduced at the bottom of crypts (d-f). iNOS immunoreactivity was hardly observed on peripherin-positive nerve cells (arrows in $\mathbf{e}, \mathbf{f}$ ), but principally observed on stromal cells in the lamina propria (arrowheads in $\mathbf{e}, \mathbf{f})$. 
Table 4 Chronological changes to the colon caused by administration of DSS

\begin{tabular}{|c|c|c|c|}
\hline & Day 0 & Early phase (days 2-3) & Late phase (days $4-5$ ) \\
\hline Pathological change & None & None $\rightarrow$ mild & Severe \\
\hline & & & and submucosa $\uparrow$ \\
\hline Vascular permeability & None & $\uparrow$ & $\uparrow \uparrow$ \\
\hline Serum VEGF expression level & Low & $\rightarrow$ & $\rightarrow$ \\
\hline Leakage of RITC-gelatin & None & In the deep layer of the lamina propria & Throughout the lamina propria \\
\hline PECAM1-positive cells & Regularly arranged in the wall of vessels & Irregularly arranged & Irregularly arranged \\
\hline aSMA-positive cells & $\begin{array}{l}\text { Regularly surrounded PECAM1-positive } \\
\text { cells in the vessel walls sporadically } \\
\text { in the lamina propria }\end{array}$ & $\begin{array}{l}\text { Irregularly in vessel walls in } \\
\text { the lamina propria } \downarrow\end{array}$ & $\begin{array}{l}\text { Irregularly in vessel walls in } \\
\text { the lamina propria } \uparrow\end{array}$ \\
\hline & & Vascular endothelial and aSMA & aSMA cells in the submucosa $\downarrow$ \\
\hline & & cells in the submucosa $\uparrow$ & Neurons in the myenteric plexus $\downarrow$ \\
\hline & & Neurons in the myenteric plexus $\uparrow$ & \\
\hline HIF1a expression level & Low & $\uparrow$ & $\downarrow$ \\
\hline \multirow[t]{4}{*}{ iNOS positivity } & None & Epithelial cells $\uparrow$ & Epithelial cells $\uparrow$ \\
\hline & & Nerve fibers in the lamina propria $\uparrow$ & Stroma cells in the lamina propria $\uparrow$ \\
\hline & & Neurons in the myenteric plexus $\uparrow$ & Nerve fibers in the lamina propria $\downarrow$ \\
\hline & & & Neurons in the myenteric plexus $\uparrow$ \\
\hline
\end{tabular}

Table 5 Chronological changes to the colonic mucosa following ligation of the inferior mesenteric vein

\begin{tabular}{llll}
\hline & 2h & 24 h later & 48 h later \\
Pathological change & None & None & Mild \\
KI67 positivity in the cells & ++ & ++ & \\
at the bottom of crypt & In the mucosal & Surface epithelial cells $\rightarrow$ & Surface epithelial cells $\uparrow$ \\
HIF1a positivity & surface epithelial & Neurons in the myenteric plexus $\uparrow$ & Vascular endothelial and aSMA cells in the submucosa $\uparrow$ \\
& cells & None & Neurons in the myenteric plexus $\uparrow$ \\
iNOS positivity & Stroma cells in the lamina propria $\uparrow$ & Stroma cells in the lamina propria $\uparrow$ \\
& Nerve fibers in the lamina propria $\uparrow$ & Nerve fibers in the lamina propria $\uparrow$ \\
& Neurons in the myenteric plexus $\uparrow$ & Neurons in the myenteric plexus $\uparrow$ \\
\hline
\end{tabular}

whether neuronal iNOS similarly plays some role in exacerbating inflammation in human UC. Butylscopolamine is contraindicated for active-stage UC, because it inhibits colonic peristaltic movement, followed by translocation of enteric bacteria and increased risk of toxic megacolon. ${ }^{55}$
Therefore, it is necessary to develop a drug that specifically inhibits neural iNOS in the colon to avoid the above risk in human applications.

In conclusion, this study is the first to demonstrate microvascular deterioration preceding epithelial disorganization in 

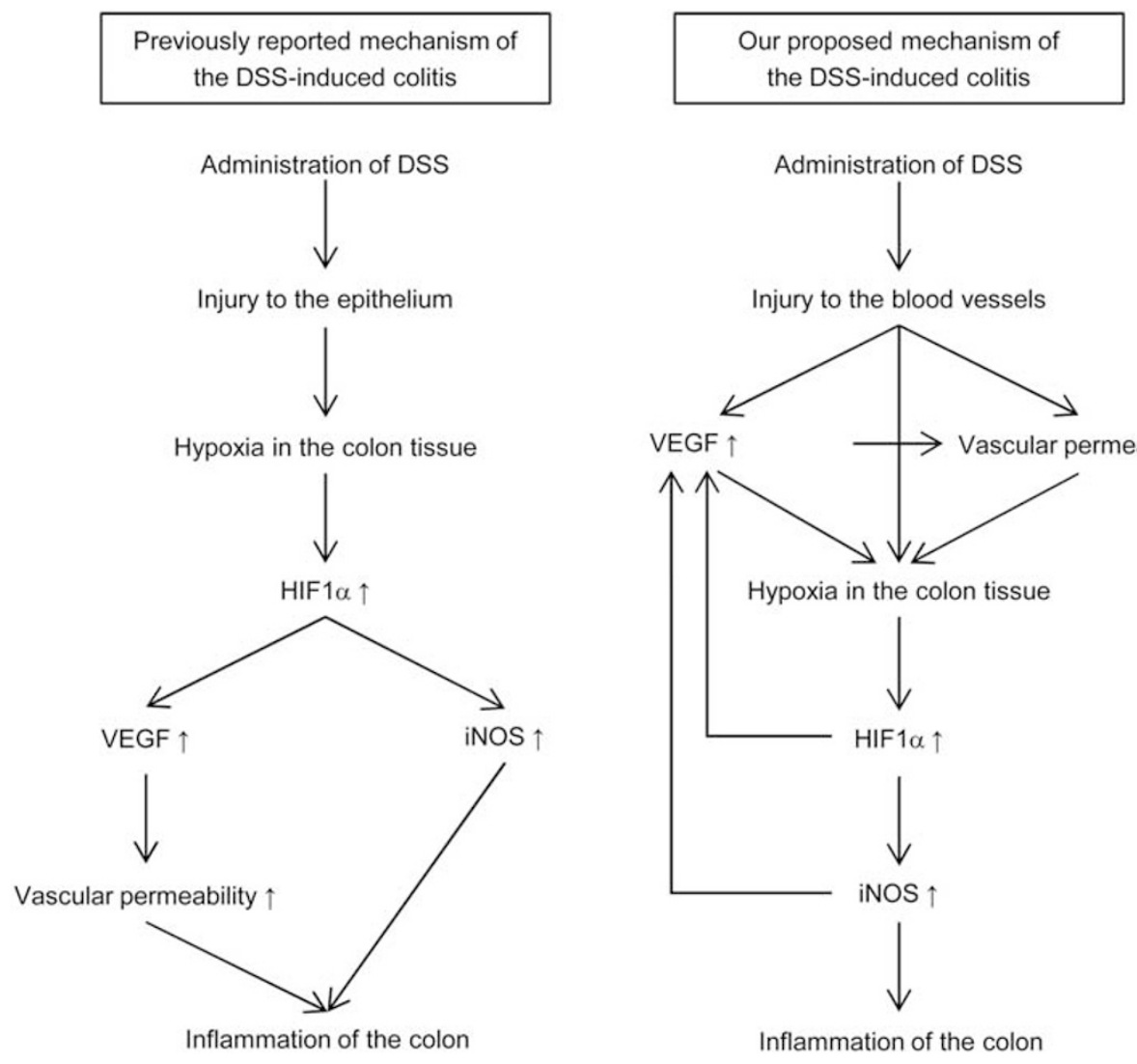

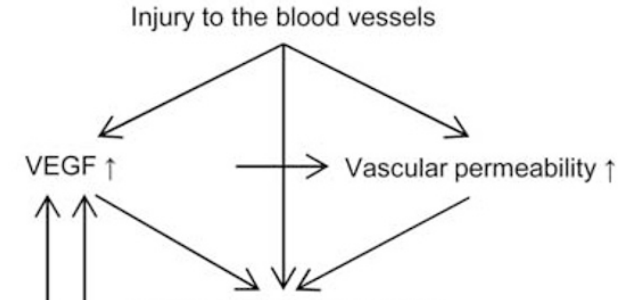

Hypoxia in the colon tissue

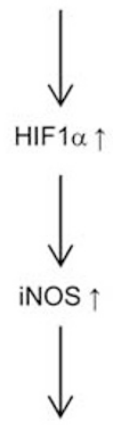

Inflammation of the colon

Figure 10 Previously reported mechanism of DSS-induced colitis vs our proposed mechanism of DSS-induced colitis.

the pathogenesis of DSS-induced colitis. These findings will aid in contextualizing future findings arising from this animal model. Furthermore, microvascular disorder may also be involved in the onset and recurrence of human UC. In recent years, endoscopic techniques have progressed, and confocal laser endoscopy has been introduced into the clinical work-up and contributes to evaluating inflammatory activity in IBD and neoplastic lesions. ${ }^{56,57}$ The bloodstream in active-stage UC is observed by injecting fluorescent dye into a blood vessel. ${ }^{58}$ Although intestinal inflammation is generally believed to spread from the superficial layer toward the deeper layer of the mucosa, vascular disorder may precede epithelial disturbance in colitis, as shown in this study. Therefore, confocal laser endoscopic observation of the vasculature may aid in the early detection of relapse of inflammation during a temporary remission of IBD.

\section{Supplementary Information accompanies the paper on the Laboratory Investigation website (http://www.laboratoryinvestigation.org)}

\section{ACKNOWLEDGMENTS}

We thank Hideaki Suzuki for advices on statistical analysis of the manuscript.

DISLOSURE/CONFLICT OF INTEREST

The authors declare no conflict of interest.

1. Khor B, Gardet A, Xavier RJ. Genetics and pathogenesis of inflammatory bowel disease. Nature 2011;474:307-317.

2. Baumgart DC, Carding SR. Inflammatory bowel disease: cause and immunobiology. Lancet 2007;369:1627-1640.

3. Jowett SL, Seal CJ, Pearce MS et al. Influence of dietary factors on the clinical course of ulcerative colitis: a prospective cohort study. Gut 2004;53:1479-1484.

4. Ko IK, Kim BG, Awadallah A et al. Targeting improves MSC treatment of inflammatory bowel disease. Mol Ther 2010;18:1365-1372.

5. Okayasu I, Hatakeyama S, Yamada M et al. A novel method in the induction of reliable experimental acute and chronic ulcerative colitis in mice. Gastroenterology 1990;98:694-702.

6. Elson CO, Sartor RB, Tennyson GS et al. Experimental models of inflammatory bowel disease. Gastroenterology 1995;109:1344-1367.

7. Dieleman LA, Beagley KW, Elson CO. The effect of immunosuppressive agents on monocyte generation and cytokine expression. Inflamm Bowel Dis 1995;1:266-275.

8. Dieleman LA, Ridwan BU, Tennyson GS et al. Dextran sulfate sodiuminduced colitis occurs in severe combined immunodeficient mice. Gastroenterology 1994;107:1643-1652.

9. Cooper HS, Murthy SN, Shah RS et al. Clinicopathologic study of dextran sulfate sodium experimental murine colitis. Lab Invest 1993;69: 238-249.

10. Kitajima S, Takuma S, Morimoto M. Tissue distribution of dextran sulfate sodium (DSS) in the acute phase of murine DSS-induced colitis. $J$ Vet Med Sci 1999;61:67-70.

11. Johansson ME, Gustafsson JK, Sjoberg KE et al. Bacteria penetrate the inner mucus layer before inflammation in the dextran sulfate colitis model. PLoS One 2010;5:e12238.

12. Nakamura $M$, Asada $M$, Matsui $H$ et al. Increased microvascular permeability in early stage of dextran sulfate sodium-induced colitis: its interaction with lansoprazole binding sites. Clin Hemorheol Microcirc 2006;34:193-199. 
13. Giaccia A, Siim BG, Johnson RS. HIF-1 as a target for drug development. Nat Rev Drug Discov 2003;2:803-811.

14. Ke Q, Costa M. Hypoxia-inducible factor-1 (HIF-1). Mol Pharmacol 2006;70:1469-1480

15. Hirota K, Semenza GL. Regulation of angiogenesis by hypoxiainducible factor 1. Crit Rev Oncol Hematol 2006;59:15-26.

16. Melillo G, Musso T, Sica A et al. A hypoxia-responsive element mediates a novel pathway of activation of the inducible nitric oxide synthase promoter. J Exp Med 1995;182:1683-1693.

17. Murthy SN, Cooper HS, Shim H et al. Treatment of dextran sulfate sodium-induced murine colitis by intracolonic cyclosporin. Dig Dis Sci 1993;38:1722-1734.

18. Moolenbeek C, Ruitenberg EJ. The "Swiss roll": a simple technique for histological studies of the rodent intestine. Lab Anim 1981;15: 57-59.

19. Hashimoto $\mathrm{H}$, Ishikawa $\mathrm{H}$, Kusakabe M. Three-dimensional analysis of the developing pituitary gland in the mouse. Dev Dyn 1998;212: 157-166.

20. Franklin RM. Pre-embedding staining for immunohistochemistry at the light microscopic level. In: Bullock GR, Petrusz P (eds). Techniques in Immunocytochemistry. Academic Press: London, UK, 1982, pp 251-268.

21. Bennett HS, Wyrick AD, Lee SW et al. Science and art in preparing tissues embedded in plastic for light microscopy, with special reference to glycol methacrylate, glass knives and simple stains. Stain Technol 1976;51:71-97.

22. Gamse $R$, Holzer $P$, Lembeck $F$. Decrease of substance $P$ in primary afferent neurones and impairment of neurogenic plasma extravasation by capsaicin. Br J Pharmacol 1980;68:207-213.

23. Saria A, Lundberg JM. Evans blue fluorescence: quantitative and morphological evaluation of vascular permeability in animal tissues. J Neurosci Methods 1983;8:41-49.

24. Martin Y, Avendaño C, Piedras MJ et al. Evaluation of Evans Blue extravasation as a measure of peripheral inflammation. Protocol Exchange from Nature Protocols, print copy in press 2013. Available from www.nature.com/protocolexchange/protocols/1919.

25. Riddle RD, Johnson RL, Laufer $\mathrm{E}$ et al. Sonic hedgehog mediates the polarizing activity of the ZPA. Cell 1993;75:1401-1416.

26. Caprara $C$, Thiersch $M$, Lange $C$ et al. HIF1A is essential for the development of the intermediate plexus of the retinal vasculature. Invest Ophthalmol Vis Sci 2011;52:2109-2117.

27. Reinhardt C, Bergentall M, Greiner TU et al. Tissue factor and PAR1 promote microbiota-induced intestinal vascular remodelling. Nature 2012;483:627-631.

28. Clarke WT, Edwards B, McCullagh KJ et al. Syncoilin modulates peripherin filament networks and is necessary for large-calibre motor neurons. J Cell Sci 2010;123:2543-2552.

29. Raufman JP, Shant J, Xie G et al. Muscarinic receptor subtype-3 gene ablation and scopolamine butylbromide treatment attenuate small intestinal neoplasia in Apcmin/+ mice. Carcinogenesis 2011;32: 1396-1402.

30. Kimura $\mathrm{H}$, Hokari $\mathrm{R}$, Miura $\mathrm{S}$ et al. Increased expression of an inducible isoform of nitric oxide synthase and the formation of peroxynitrite in colonic mucosa of patients with active ulcerative colitis. Gut 1998;42: 180-187.

31. Beck PL, Xavier R, Wong J et al. Paradoxical roles of different nitric oxide synthase isoforms in colonic injury. Am J Physiol Gastrointest Liver Physiol 2004;286:G137-G147.

32. Senger DR, Galli SJ, Dvorak AM et al. Tumor cells secrete a vascular permeability factor that promotes accumulation of ascites fluid. Science 1983;219:983-985.

33. da Silva AP, Ellen RP, Sørensen ES et al. Osteopontin attenuation of dextran sulfate sodium-induced colitis in mice. Lab Invest 2009;89: 1169-1181

34. Chassaing B, Aitken JD, Malleshappa $M$ et al. Dextran sulfate sodium (DSS)-induced colitis in mice. Curr Protoc Immunol 2014;104 Unit-15.25.
35. Boismenu R, Chen Y. Insights from mouse models of colitis. J Leukoc Biol 2000;67:267-278.

36. Kurashima $Y$, Amiya $T$, Nochi $T$ et al. Extracellular ATP mediates mast cell-dependent intestinal inflammation through P2X7 purinoceptors. Nat Commun 2012;3:1034.

37. Griffen TS, Hagihara PF. Ischemic colitis in rats. Dis Colon Rectum 1982;25:638-640.

38. Irkorucu O, Tascilar O, Cakmak GK et al. The effect of sildenafil on an animal model for ischemic colitis. Dig Dis Sci 2008;53:1618-1623.

39. Cromer WE, Ganta CV, Patel M et al. VEGF-A isoform modulation in an preclinical TNBS model of ulcerative colitis: protective effects of a VEGF164b therapy. J Transl Med 2013;11:207.

40. Trojanowska M. Cellular and molecular aspects of vascular dysfunction in systemic sclerosis. Nat Rev Rheumal 2010;6:453-460.

41. Furness JB. Types of neurons in the enteric nervous system. J Auton Nerv Syst 2000;81:87-96.

42. Bock F, Onderka J, Dietrich T et al. Bevacizumab as a potent inhibitor of inflammatory corneal angiogenesis and lymphangiogenesis. Invest Ophthalmol Vis Sci 2007;48:2545-2552.

43. Tolstanova G, Khomenko T, Deng $X$ et al. Neutralizing anti-vascular endothelial growth factor (VEGF) antibody reduces severity of experimental ulcerative colitis in rats: direct evidence for the pathogenic role of VEGF. J Pharmacol Exp Ther 2009;328:749-757.

44. Matsuura M, Okazaki K, Nishio A et al. Therapeutic effects of rectal administration of basic fibroblast growth factor on experimental murine colitis. Gastroenterology 2005;128:975-986.

45. Dijkstra G, Zandvoort AJ, Kobold AC et al. Increased expression of inducible nitric oxide synthase in circulating monocytes from patients with active inflammatory bowel disease. Scand J Gastroenterol 2002;37:546-554.

46. Yoshida $Y$, Iwai $A$, Itoh $K$ et al. Role of inducible nitric oxide synthase in dextran sulphate sodium-induced colitis. Aliment Pharmacol Ther 2000;14:26-32.

47. Aoi $\mathrm{Y}$, Terashima S, Ogura M et al. Roles of nitric oxide (NO) and NO synthases in healing of dextran sulfate sodium-induced rat colitis. J Physiol Pharmacol 2008;59:315-336.

48. McCafferty DM, Miampamba M, Sihota $\mathrm{E}$ et al. Role of inducible nitric oxide synthase in trinitrobenzene sulphonic acid induced colitis in mice. Gut 1999;45:864-873.

49. Shifrin H, Nadler-Milbauer M, Shoham S et al. Rivastigmine alleviates experimentally induced colitis in mice and rats by acting at central and peripheral sites to modulate immune responses. PLoS One 2013;8:e57668.

50. Alleva E, Bignami G. Development of mouse activity, stimulus reactivity, habituation, and response to amphetamine and scopolamine. Physiol Behav 1985;34:519-523.

51. Estape N, Steckler T. Cholinergic blockade impairs performance in operant DNMTP in two inbred strains of mice. Pharmacol Biochem Behav 2002;72:319-334.

52. Abe $H$, Ishikawa W, Kushima $T$ et al. Nitric oxide induces vascular endothelial growth factor expression in the rat placenta in vivo and in vitro. Biosci Biotechnol Biochem 2013;77:971-976.

53. Ni J, Chen SF, Hollander D. Effect of dextran sulfate sodium on intestinal epithelial cells and intestinal lymphocytes. Gut 1996;39: 234-241.

54. Mizoguchi A, Mizoguchi E. Inflammatory bowel disease, past, present and future: lessons from animal models. J Gastroenterol 2008;43:1-17.

55. Gan SI, Beck PL. A new look at toxic megacolon: an update and review of incidence, etiology, pathogenesis, and management. Am J Gastroenterol 2003;98:2363-2371.

56. Hoffman A, Goetz M, Vieth $M$ et al. Confocal laser endomicroscopy: technical status and current indications. Endoscopy 2006:38:1275-1283.

57. Watanabe O, Ando T, Maeda $\mathrm{O}$ et al. Confocal endomicroscopy in patients with ulcerative colitis. J Gastroenterol Hepatol 2008;23: S286-S290.

58. Neumann $\mathrm{H}$, Kiesslich $\mathrm{R}$, Wallace $\mathrm{MB}$ et al. Confocal laser endomicroscopy: technical advances and clinical applications. Gastroenterology 2010;139:388-392 92 e1-2. 